\title{
Factors Affecting the Inland and Orographic Enhancement of Sea-Effect Snowfall in the Hokuriku Region of Japan
}

\author{
Peter G. Veals and W. James Steenburgh \\ Department of Atmospheric Sciences, University of Utah, Salt Lake City, Utah \\ Sento NAKai AND SATORU YAmAgUCHI \\ Snow and Ice Research Center, National Research Institute for Earth Science and Disaster Resilience, Nagaoka, \\ Japan
}

(Manuscript received 8 January 2019, in final form 6 June 2019)

\begin{abstract}
The Hokuriku region along the west coast of the Japanese island of Honshu receives exceptionally heavy snowfall accumulations, exceeding $500 \mathrm{~cm}$ from December to February near sea level and $1300 \mathrm{~cm}$ at high elevation sites, much of which is produced by sea-effect systems. Though the climatological enhancement of snowfall is large, the lowland-upland snowfall distribution within individual storms is highly variable, presenting a challenge for weather forecasting and climate projections. Utilizing data from a C-band surveillance radar, the ERA5 reanalysis, and surface precipitation observations, we examine factors affecting the inland and orographic enhancement during sea-effect periods in the Hokuriku region during nine winters (December-February) from December 2007 to February 2016. The distribution and intensity of precipitation exhibits strong dependence on flow direction due to three-dimensional terrain effects. For a given flow direction, higher values of boundary layer wind speed and sea-induced CAPE favor higher precipitation rates, a maximum displaced farther inland and higher in elevation, and a larger ratio of upland to lowland precipitation. These characteristics are also well represented by the nondimensional mountain height $\hat{H}$, with $\hat{H}<1$ associated with a precipitation maximum over the high elevations and a larger ratio of upland to lowland precipitation, and $\hat{H}>1$ having the opposite effect. Nevertheless, even in high enhancement periods, precipitation rates decline as one moves inland from the first major mountain barrier, even over high terrain. These results highlight how the interplay between sea-effect and orographic processes modulates the distribution and intensity of precipitation in an area of complex and formidable topography.
\end{abstract}

\section{Introduction}

The Hokuriku region along the west coast of the Japanese island of Honshu observes frequent and often intense sea-effect precipitation during the cool season. Due in large part to this sea-effect precipitation, mean December-February snowfall ranges from $\sim 500 \mathrm{~cm}$ in the coastal lowlands to $1300 \mathrm{~cm}$ or more at mountain locations, with corresponding liquid precipitation equivalent (LPE) amounts of $\sim 100$ and $200 \mathrm{~cm}$, respectively (JMA 2018; Nakai and Yamaguchi 2018). Snow depths can reach as great as $2 \mathrm{~m}$ in major lowland cities and $7 \mathrm{~m}$ in the adjacent mountains (Yamaguchi et al. 2011). The precipitation distribution within individual storms is, however, highly variable. Some storms

Corresponding author: Peter G. Veals, peter.veals@utah.edu produce heavier precipitation in the coastal lowlands, whereas others favor higher terrain (e.g., Magono et al. 1966; Akiyama 1981a,b; Ishihara et al. 1989; Nakai and Endoh 1995; Tachibana 1995; Eito et al. 2005; Nakai et al. 2006; Iwamoto et al. 2008).

Veals et al. (2018, hereafter V18) recently examined the factors controlling such precipitation variations downstream of Lake Ontario of North America where lake-effect systems interact with the Tug Hill Plateau (hereafter Tug Hill). They found that the strength of the incident boundary layer flow, the lake-effect precipitation mode, and the lake-induced convective available potential energy (LCAPE) influence the distribution and inland and orographic enhancement of precipitation. However, Tug Hill is an isolated, gently sloping terrain feature that rises only $500 \mathrm{~m}$ above Lake Ontario, which has a maximum fetch of only $\sim 300 \mathrm{~km}$. 

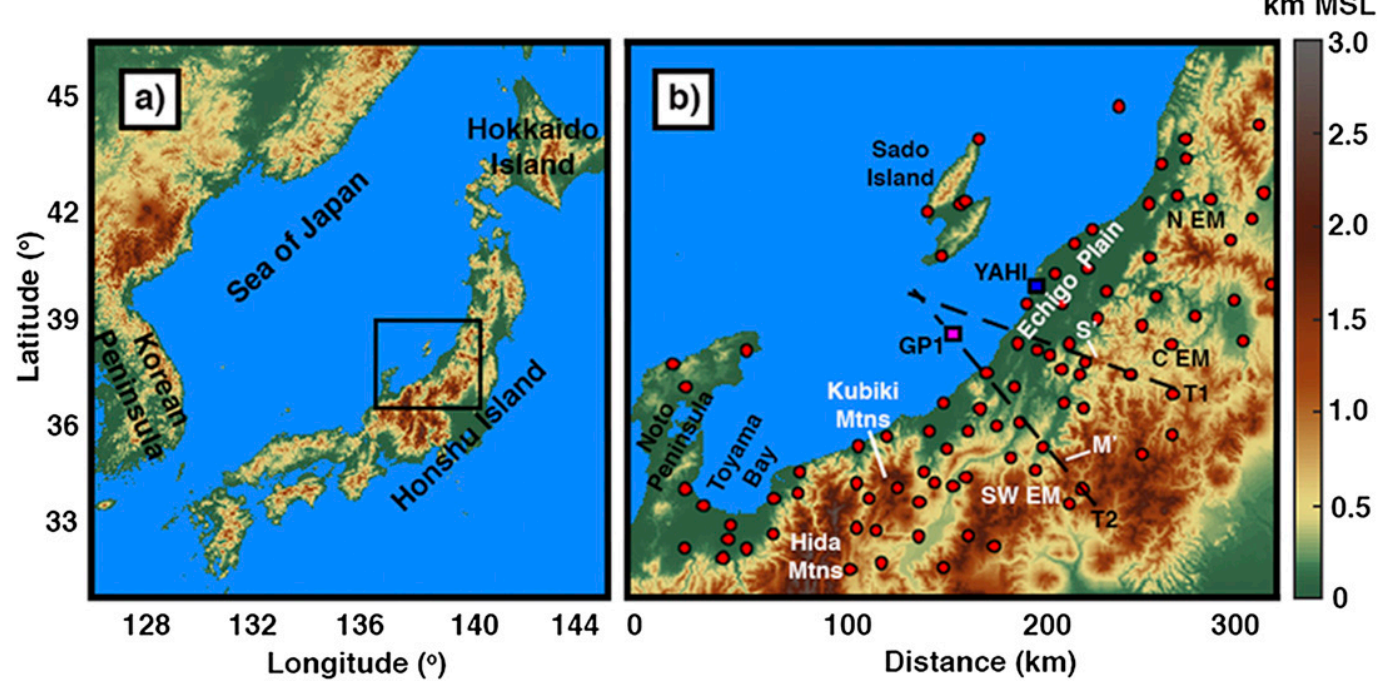

FIG. 1. Topography (km MSL following scale at right) of (a) the Sea of Japan region, with the location of the inset indicated by the black box, and (b) the study region. The locations of JMA and SIRC surface observing sites indicated by red dots, the location of the YAHI radar indicated by the blue circle, and the location of the ERA5 grid point (GP1) used for atmospheric and sea surface conditions indicated by the magenta square. Transects 1 and 2 indicated by the dashed lines labeled T1 and T2 with Mt. Sumon and Mt. Makihata indicated by $\mathrm{S}^{\prime}$ and $\mathrm{M}^{\prime}$, respectively. The southwest, central, and northern Echigo Mountains indicated by SW EM, C EM, and N EM, respectively.

The Hokuriku region, on the other hand, features diverse topography that includes a broad coastal plain bordered by mountain barriers reaching $1500-3000 \mathrm{~m}$ MSL (Fig. 1). In addition, the Sea of Japan (hereafter SOJ) is a large body of water with a fetch $\sim 850 \mathrm{~km}$ that produces nearly omnipresent sea-effect precipitation during the winter.

The sea-effect precipitation affecting the Hokuriku region occurs primarily during the East Asian winter monsoon, which produces frequent cold-air outbreaks over the relatively warm SOJ (Mizukoshi 1977; Boyle and Chen 1987; Dorman et al. 2004; Chang et al. 2006). The proportion of precipitation falling as snow at low elevations increases as one moves poleward along west coast of Honshu (Inoue and Yokoyama 1998). During cold-air outbreaks, the large fetch over the SOJ also allows for the growth of a planetary boundary layer (PBL) that is typically deeper than found over smaller bodies of water. For example, studies in and near the Hokuriku region document PBL depths of 2.5-6 km (e.g., Manabe 1957; Nagata et al. 1986; Yoshihara et al. 2004; Ohigashi and Tsuboki 2005; Nakai et al. 2006; Ohigashi et al. 2014), whereas Byrd et al. (1991) observed PBL depths of 1.5-3.1 km during lake-effect events produced by Lake Ontario.

The morphology of sea-effect precipitation systems features a variety of modes over and upstream of the Hokuriku region (Nakai et al. 2005).
Most common are wind-parallel bands that are oriented along the prevailing flow and are known as longitudinal or "L-mode" bands. Such bands are similar to wind-parallel bands over the Laurentian Great Lakes (e.g., Kelly 1984; Kristovich 1993; Kristovich et al. 1999; Cooper et al. 2000), produced by horizontal roll convection, and occur during periods of weak directional shear within the PBL (Asai 1972; Miura 1986; Yamada et al. 2010). During periods of strong directional shear, the roll convection can orient and produce bands normal to the prevailing flow (Tsuchiya and Fujita 1967; Asai 1972; Eito et al. 2010; Campbell et al. 2018). Such transverse or "T-mode" bands are less common than L-mode bands, but during one cool season were observed during $\sim 12 \%$ of the seaeffect periods (Nakai et al. 2005).

The Japan Sea polar airmass convergence zone (JPCZ) frequently forms over the western SOJ downstream of the base of the Korean Peninsula and often generates a deeper, broader, and more intense band of sea-effect precipitation (e.g., Ohigashi and Tsuboki 2007; Eito et al. 2010; West et al. 2019). It is initiated and maintained by the thermal contrast between the Korean Peninsula and the SOJ, the characteristic distribution of sea surface temperature (SST) in the SOJ, and convergence in the lee of high terrain of the upper Korean Peninsula (e.g., Nagata et al. 1986; Nagata 1991). The JPCZ can produce intense precipitation 
where it intersects the coast of Honshu, most frequently between $\sim 133^{\circ}$ and $\sim 139^{\circ} \mathrm{E}$, including the Hokuriku region (Eito et al. 2010). During sea-effect periods, the SOJ can also produce warm-core vortices with horizontal dimensions spanning the mesoscale, including polar lows (e.g., Ninomiya et al. 1993; Ninomiya 1994; Fu et al. 2004; Watanabe and Niino 2014; Yanase et al. 2016).

Once the sea-effect precipitation features reach the downstream coastline, a number of coastal and topographic effects modify the distribution and intensity of the precipitation. Peninsulas and offshore islands can generate convergence and precipitation (e.g., Miyazawa 1968; Fujiyoshi et al. 1992; Yoshihara et al. 2004; Ohtake et al. 2009; Campbell et al. 2018) or, alternatively, terrain shadowing (Yagi and Uchiyama 1983; Takada 2003). Along the west coast of Japan, offshore katabatic flow can oppose the large-scale flow, reinforcing convergence along the land-breeze front and producing a precipitation maximum along or off the coast (e.g., Ishihara et al. 1989; Eito et al. 2005). Tachibana (1995) found this scenario to be associated with weaker largescale flow and colder upper-tropospheric temperatures, and to be most pronounced during the coldest part of the winter and in the early morning hours.

The distribution of precipitation is also heavily influenced by the topography of the Hokuriku region, which includes the coastal Echigo Plain and the Hida, Kubiki, and Echigo Mountains (Fig. 1). The Hida and Kubiki Mountains demarcate the southwest end of the Echigo Plain and are oriented quasi meridionally with the highest peaks reaching over 3000 and $2400 \mathrm{~m}$ MSL, respectively. Inland from the Echigo Plain, the southwest Echigo Mountains form a high, quasi-continuous barrier with many peaks reaching $\sim 2000 \mathrm{~m}$ MSL. The central Echigo Mountains are lower and less continuous, with peaks reaching $\sim 1000-1500 \mathrm{~m}$. Finally, multiple ranges compose the northern Echigo Mountains, with the highest peaks reaching $\sim 2000 \mathrm{~m}$ MSL.

Given such prominent topography, the interplay between the barrier-normal flow and the static stability likely becomes crucial in determining the precipitation distribution, as frequently evaluated using the nondimensional mountain height (or inverse Froude number), defined as

$$
\hat{H}=\frac{N_{d} h_{m}}{U},
$$

where $N_{d}$ is the dry Brunt-Väisälä frequency, $h_{m}$ is the height of the barrier, and $U$ is the component of the wind speed normal to the barrier (e.g., Pierrehumbert and Wyman 1985; Baines 1987; Smith 1988; Markowski and Richardson 2010). For saturated flow, stability can be accounted for using the moist Brunt-Väisälä frequency, $N_{m}$ (e.g., Fraser et al. 1973; Barcilon et al. 1979; Durran and Klemp 1982; Jiang 2003). For barriers that are elongated in the flow-normal direction, values of $\hat{H} \ll 1$ are generally associated with unblocked flow surmounting the barrier, with increasing flow deceleration as $\hat{H} \rightarrow 1$, the beginning of flow stagnation for $\hat{H} \cong 1$, and blocking and flow deflection along or around the barrier for $\hat{H} \gg 1$ (e.g., Markowski and Richardson 2010). Ohigashi et al. (2014) examined the effect of $\hat{H}$, calculated from a nearby sounding site, upon a coastal band that produced heavy lowland precipitation in the Hokuriku region and found that the flow was blocked by the coastal terrain from the surface to heights between 1 and $2 \mathrm{~km} \mathrm{MSL}$. Similarly, Kusunoki et al. (2004) describe a sea-effect event that began with strongly blocked (high $\hat{H}$ ) conditions and shallow clouds confined to the lower elevations, transitioned to lower $\hat{H}$ with deeper clouds reaching farther up the mountain slopes, and ended with increasing $\hat{H}$ and shallow clouds confined to the middle and lower slopes.

By examining the factors affecting the distribution and enhancement of sea-effect precipitation in the Hokuriku region, this study aims to improve the understanding and prediction of lake- and sea-effect precipitation in regions of complex terrain and to contribute to the general understanding of terrain influences on precipitation. The next section describes the data and methods used, section 3 describes the effects of boundary layer wind direction, section 4 examines the effects of boundary layer wind speed, section 5 discusses the effect of $\hat{H}$, and section 6 examines the effects of sea-induced convective available potential energy (SiCAPE). Section 7 presents the combined effects of SiCAPE and boundary layer wind speed, and section 8 concludes the paper with a summary and discussion of results.

\section{Data and methods}

\section{a. Radar data and identification of sea-effect periods}

We identify and describe the characteristics of seaeffect precipitation in the Hokuriku region using nine winters (December-February from December 2007 to February 2016) of radar reflectivity data from the Japan Meteorological Agency (JMA) C-band surveillance radar, YAHI, located at $645 \mathrm{~m}$ MSL on Mt. Yahiko (Fig. 1b). YAHI is well positioned to detect precipitation over the nearby SOJ, Echigo Plain, and adjacent mountains, although there is blockage of lower elevation scans where the beam intersects 
higher terrain (Fig. 2). Data were obtained from the JMA in a format similar to the Level II format of the National Weather Service WSR-88D network (Crum et al. 1993), with a minimum elevation angle of $-0.5^{\circ}$, additional scans up to a maximum elevation angle of $25^{\circ}$, and full volumes available at 10 -min intervals.

Following V18, we interpolated the volume scans to a Cartesian grid with $0.01^{\circ}$ horizontal and $0.25-\mathrm{km}$ vertical grid spacing using the $\mathrm{Radx} \mathrm{C}++$ software package (Earth Observing Laboratory 2019). Grid cells located within $500 \mathrm{~m}$ of the ground were masked out to decrease the presence of artifacts in the reflectivity field, but due to the extrapolation and assumptions of beam characteristics required to convert radar data to a 3D Cartesian grid, such artifacts cannot be eliminated completely. Radar-estimated LPE was derived using the $Z-S$ relationship described by Vasiloff (2001) and Campbell et al. (2016), given by

$$
Z=75 S^{2},
$$

where $Z$ is the lowest-level radar reflectivity factor $\left(\mathrm{mm}^{6} \mathrm{~m}^{-3}\right)$ and $S$ is the LPE rate $\left(\mathrm{mm} \mathrm{h}^{-1}\right)$. We tested a number of relationships, including those developed by Nakai et al. (2018) for an X-band radar in the Hokuriku region and Fujiyoshi et al. (1990) for a C-band radar in the Hokkaido region, but found the Vasiloff (2001) relationship designed for S-band radars to be closest to the gauge-measured precipitation, with the highest Pearson correlation coefficient (hereafter CC) and lowest rootmean-square error. The radar-derived LPE rates are presented with gauge measurements to illustrate the uncertainty in LPE estimation. Because YAHI scans over the SOJ with elevation angles as low as $-0.5^{\circ}$, we filtered sea clutter using the method of Steiner and Smith (2002).

We focus our analysis on sea-effect periods, defined following literature from the Great Lakes (e.g., Niziol et al. 1995) and the SOJ (West et al. 2019) as those with a sea surface to 850 -hPa temperature difference, $\Delta T_{\text {Sea }-850}, \geq 13^{\circ} \mathrm{C}$. Our analysis is further restricted to periods with temperatures $<0^{\circ} \mathrm{C}$ at and above $975 \mathrm{hPa}$ to mitigate brightband contamination of the radar reflectivity. The sea surface and atmospheric temperature data were obtained from the ERA5 reanalysis (ECMWF 2017), available at 31-km horizontal grid spacing and 1-h temporal resolution, with the values from a single grid point (GP1) utilized for calculations (Fig. 1). V18 used a horizontal mean within a rectangle spanning the study area for their calculations, but we found variables calculated using data from GP1 had the strongest relationship with the LPE distribution in the Hokuriku region relative to

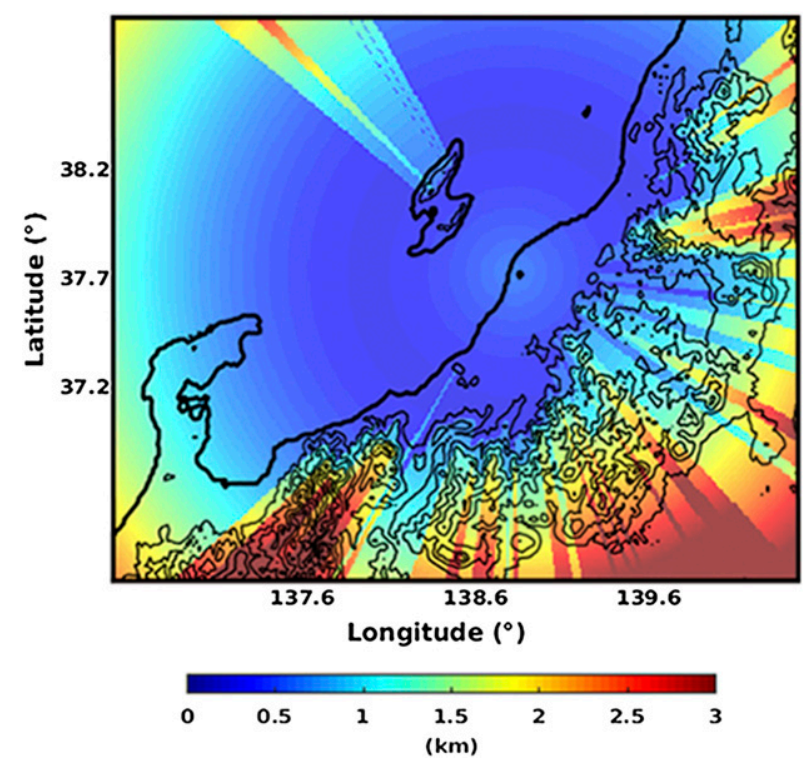

FIG. 2. Height MSL $(\mathrm{km})$ of the centroid of the lowest unblocked YAHI beam assuming standard atmospheric refraction conditions (4/3 Earth radius) with terrain elevation contours every $400 \mathrm{~m}$ MSL.

other grid points or averaging boxes. Radar scans were partitioned using the closest ERA5 analysis time, yielding a maximum difference of $30 \mathrm{~min}$ between the reanalysis time and the radar scan. Although the $13^{\circ} \mathrm{C}$ threshold may exclude some periods of sea-effect precipitation and include some periods of non-seaeffect precipitation, manual examination of events on either side of the threshold found it to be a good discriminator.

\section{b. Environmental conditions}

We focus on four variables that influence the inland and orographic enhancement of sea-effect precipitation: 1) the mean boundary layer wind direction, 2) the mean boundary layer wind speed $\bar{U}, 3) \hat{H}$, and 4) SiCAPE. The mean direction and speed of the boundary layer flow influence the location, intensity, and inland penetration of lake-effect precipitation (e.g., Alcott and Steenburgh 2013; Villani et al. 2017; V18). They are also integral to orographic precipitation processes, with stronger crossbarrier flow associated with a greater upslope moisture flux and decreased blocking (e.g., Sinclair et al. 1997; Neiman et al. 2002; Colle 2004; Panziera and Germann 2010; Yuter et al. 2011). $\hat{H}$ provides a precise quantification of the terrain-induced flow behavior, accounting for barrier height, the barrier-normal flow component, and the static stability of the impinging air mass. SiCAPE provides an estimate of the energy available for convection. Larger SiCAPE favors more intense cells, greater LPE rates, and greater moistening of the air 
mass, all of which would have implications for the precipitation distribution.

Atmospheric and surface variables were obtained from the ERA5 reanalysis at GP1. For calculations of $\hat{H}$, we utilized data on the original 137 model vertical levels, as the high vertical resolution in the lower troposphere was necessary for a calculation so sensitive to lapse rate. For calculations of $\bar{U}$ and SiCAPE, we utilized data on pressure levels with a vertical resolution of $25 \mathrm{hPa}$, as this was sufficient and more comparable to the data used in V18 for their calculations of $\bar{U}$ and LCAPE.

We define $\bar{U}$ as the wind composed of the mean $u$ and mean $v$ wind components, with the mean calculated from 950 to $800 \mathrm{hPa}$. V18 averaged from 950 to $850 \mathrm{hPa}$ because $850 \mathrm{hPa}$ is often near the top of the PBL during lake-effect periods over Lake Ontario, but we found that averaging from 950 to $800 \mathrm{hPa}$ produced better results in the Hokuriku region where the PBL during sea-effect periods is typically deeper. V18 also defined $\bar{U}$ as the component of the flow along their zonally oriented transect, but since we explore a variety of flow directions, our definition of $\bar{U}$ is a vector, with both a speed and direction.

$\hat{H}$ can be calculated a number of ways, with no method clearly optimal (e.g., Reinecke and Durran 2008). We experimented with a number of options and utilize a method similar to the second method of Reinecke and Durran (2008), which had the strongest effect upon the precipitation distribution, though a method similar to that of Ohigashi et al. (2014) yielded comparable results. We set $h$ equal to the approximate height of the highest terrain along each transect considered, with $h=1500 \mathrm{~m}$ and $h=2000 \mathrm{~m}$ used for the two transects presented. For $N$, we average $N_{d}^{2}$ at all levels between $200 \mathrm{~m}$ and $h$ and take the square root, as in the second method of Reinecke and Durran (2008). We attempted to use $N_{m}$ at levels where relative humidity exceeded various thresholds, but this method yielded a weaker signal in the LPE distribution, therefore we utilize $N_{d}$ in all calculations. The use of $N_{d}$ for moist flows is admittedly problematic, but some regions of the impinging flow are unsaturated (i.e., below cloud base and between cloud streets or cells), and it has been shown that such a flow can exhibit behavior more similar to that of a dry flow than a saturated flow (Durran and Klemp 1983). Due the frequent presence of near-surface superadiabatic lapse rates at GP1 in the ERA5, we utilize $200 \mathrm{~m}$ as the bottom of the averaging interval instead of $0 \mathrm{~m}$ to eliminate imaginary values of $N$. For $U$, we take the component of the flow parallel to the transect at each level (either T1 or T2) and average this from $200 \mathrm{~m}$ to $h$.
SiCAPE is identical to the LCAPE parameter found by V18 to affect the inland and orographic enhancement downstream of Lake Ontario, except that the "Si" is used denote the use of SST instead of lakesurface temperature. It represents an estimate of the thermodynamic forcing and environment for sea-effect convection, and affects the intensity of the convection and resulting LPE rates (e.g., Niziol 1987; Steiger et al. 2009; V18). SiCAPE is calculated using ERA5 temperature profiles and SST, and is defined as

$$
\mathrm{SiCAPE}=\int_{\mathrm{SFC}}^{\mathrm{LNB}} g\left(\frac{T_{\text {parcel }}-T_{\text {env }}}{T_{\mathrm{env}}}\right) d z,
$$

where $T_{\text {parcel }}$ is the parcel temperature $(\mathrm{K})$, initialized to the ERA5 SST at GP1 with $100 \%$ relative humidity, $T_{\text {env }}$ is the environmental temperature (K) from the GP1 profile, $g=9.81 \mathrm{~m} \mathrm{~s}^{-2}$, SFC is the surface, and LNB is the level of neutral buoyancy $(\mathrm{m})$. Because it assumes an air parcel with a temperature and dewpoint equal to the SST, SiCAPE is likely an overestimate of the actual CAPE, but is used here to represent the variation in instability from case to case.

Though there is some relation between $\bar{U}$ and SiCAPE (CC of 0.47), they exhibit sufficient independence to justify their utility for the purposes of this work (Fig. 3a). The same is true of $\bar{U}$ and $\hat{H}$, which are intrinsically related and slightly more correlated (CC of 0.53 ; Fig. 3b), but $\hat{H}$ is also important because it provides a theoretical prognosis of the propensity of flow to move over or around a barrier.

Additional variables examined but not utilized include the difference between the SST and a mean of the observed 2-m temperature at surface observing sites $\left(\Delta T_{\text {Sea }- \text { Land }}\right), \Delta T_{\text {Sea-850 }}$, the $950-800-\mathrm{hPa}$ wind shear, the time of day/year under low $\bar{U}$ conditions, the cross-barrier boundary layer vapor transport (CBVT; based on the 950-800-hPa layer), and the depth of the PBL. As was the case in V18, $\Delta T_{\text {Sea-Land }}$ and $\Delta T_{\text {Sea-850 }}$ had a weaker influence on the distribution of precipitation than SiCAPE, which is strongly correlated with $\Delta T_{\mathrm{Sea}-\mathrm{Land}}$ and implicitly accounts for $\Delta T_{\text {Sea-850. Vertical wind shear has been }}$ suggested by some studies to affect the intensity lakeeffect systems (e.g., Niziol 1987; Niziol et al. 1995), and we did indeed find high 950-800-hPa wind shear to have an effect upon the LPE distribution, but it was small compared to $\bar{U}, \hat{H}$, and SiCAPE. The time of day/year was suggested by Tachibana (1995) to have an effect upon the LPE distribution during periods of weak flow, but we found the effect to be relatively minor. A number of studies show that CBVT and similar variables modulate the distribution and intensity of 

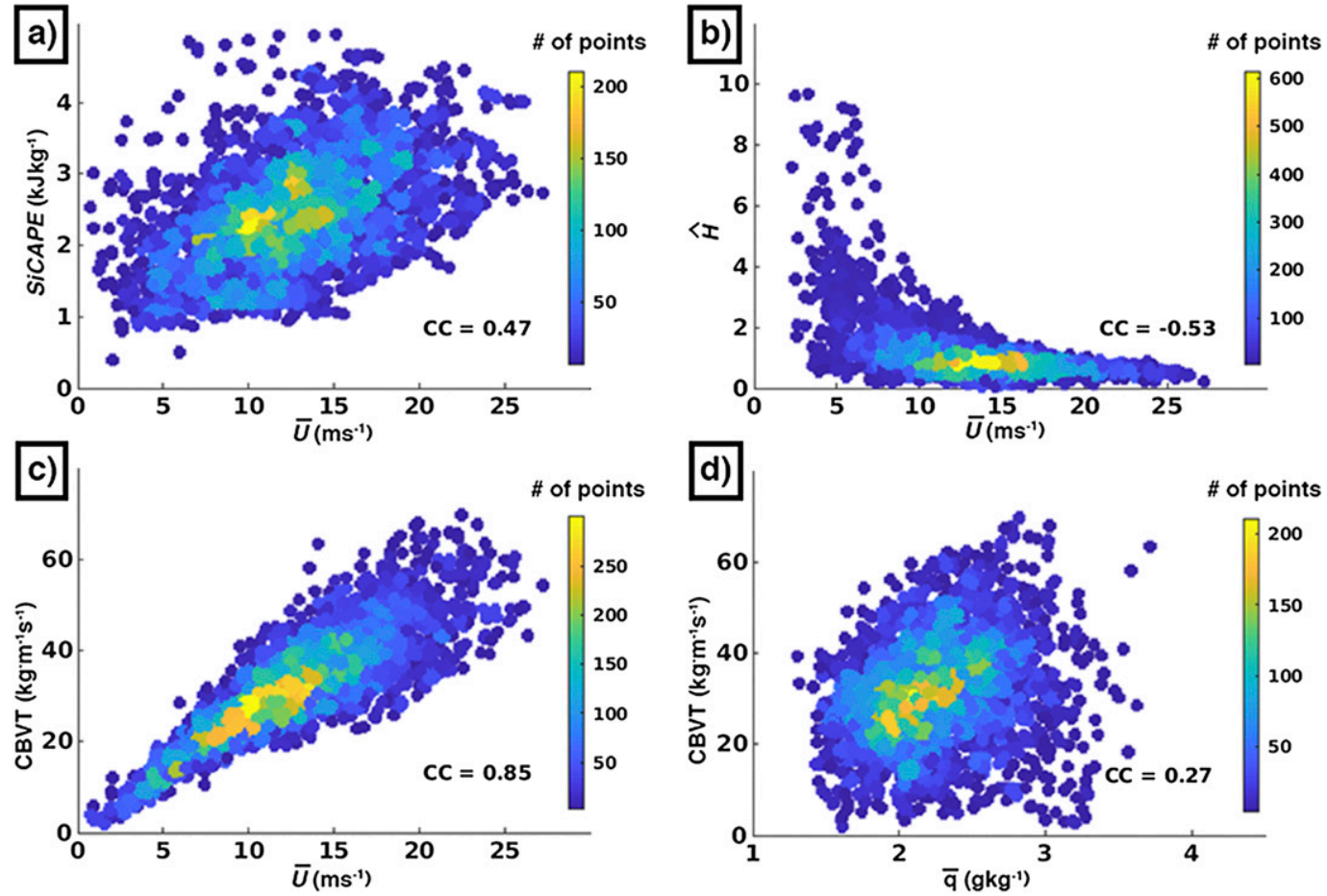

FIG. 3. For sea-effect periods with a boundary layer wind direction aligned within $10^{\circ}$ of $290^{\circ}$, scatterplots of (a) SiCAPE vs $\bar{U}$, (b) $\hat{H}$ vs $\bar{U}$ (c) CBVT vs $\bar{U}$, and (d) CBVT vs $\bar{q}$, with the Pearson correlation coefficient of each pair of variables (CC) displayed in the lower right corner of each plot. Each plot is divided into bins measuring $1 / 50$ th the domain in the $x$ direction and 1/50th the domain in the $y$ direction, and the coloring of the dots corresponds to the density of data points in each bin.

orographic precipitation (e.g., Minder et al. 2008; Rutz et al. 2014; Purnell and Kirshbaum 2018), but we found its effect on the LPE distribution was nearly identical to that of $\bar{U}$ due to their strong correlation (Fig. 3c). The other component of CBVT, the mean 950-800-hPa specific humidity $(\bar{q})$, had a relatively weak correlation with CBVT (Fig. 3d). Finally, we considered PBL depth, calculated using a number of approaches (see Von Engeln and Teixeira 2013 for a summary), but found its influence to be weaker than $\hat{H}$ and SiCAPE, both of which are influenced by the PBL structure and characteristics. V18 found lake-effect mode to affect the enhancement of lake-effect LPE in the Tug Hill region, but due to the complex spectrum of modes in the Hokuriku region and overwhelming size of the dataset, we elected not to consider mode in the present study, leaving the topic for future research.

\section{c. Surface observations}

To supplement the radar-derived LPE, LPE data were obtained from 88 JMA surface observing sites within the study region. The sites report hourly and include data-quality flags for each hour. A total of 85 sites with $<4 \%$ missing or flagged data were utilized, with the others discarded. The gauges are heated tipping buckets with a data resolution of $0.5 \mathrm{~mm}$ (Goodison et al. 1998; Yokoyama et al. 2003).

Wind shielding varied during the study period. Some sites were unshielded for a portion or the entire study period, with shielding added to reduce undercatch of precipitation, which can decrease LPE totals by $50 \%$ or more relative to a reference amount, an effect that is most pronounced for high wind speeds and low snow densities (e.g., Smith 2009; Rasmussen et al. 2012). Some sites had the shield removed during the period to mitigate spurious accumulations from capping of snowfall on the shield and its attachment arms, and subsequent bridging over or accumulation into the gauge. This phenomenon generally occurs during periods of low wind speed and heavy snowfall. Data for the presence and installation and/or removal date of shielding are available for 42 of the 85 sites, with 10 sites shielded for the duration of the period, 20 sites unshielded, and 12 sites having had a shield either installed or removed during the period. We conducted our analysis for gauges with and without shielding and there was no discernable difference in the bias relative to radar-derived LPE. Aside from 
the artifacts and biases introduced by the presence or lack of shielding, heated tipping-bucket gauges also exhibit a low bias relative to weighing gauges due to factors such as wetting loss and evaporation (e.g., Metcalfe and Goodison 1993; Rasmussen et al. 2012).

Precipitation measurements from five additional sites maintained by the Japanese National Research Institute for Earth Science and Disaster Resilience (NIED) Snow and Ice Research Center (SIRC) were also utilized. These sites are similar to those of the SW-Net type described in Yamaguchi et al. (2011), with precipitation measured by a heated tipping-bucket gauge with a wind shield.

\section{d. Quantification of inland and orographic enhancement}

We present the LPE distribution and radar statistics along two transects to quantify the inland and orographic enhancement. Transect T1 is oriented parallel to a $290^{\circ}$ flow, traverses the Echigo Plain, and extends into the central Echigo Mountains. (Fig. 1b). The highest peak along T1, Mt. Sumon, reaches $1500 \mathrm{~m}$ MSL. Transect T2 is oriented parallel to a $320^{\circ}$ flow and extends into the southwest Echigo Mountains, traversing lowland hills up to $600 \mathrm{~m}$ MSL and the $2000 \mathrm{~m}$ MSL summit of Mt. Makihata. For both transects, higher terrain exists farther downstream, but is beyond reliable radar coverage and in most cases the heaviest sea-effect precipitation. Following V18, we calculate four radar-derived variables along each transect. $\overline{\mathrm{LPE}}$ is the transect-mean radar-estimated precipitation rate $\left(\mathrm{mm} \mathrm{h}^{-1}\right)$. The inland displacement, InDisp, is the distance $(\mathrm{km})$ from the shoreline to the LPE rate maximum. The enhancement ratio, ER, is ratio of the maximum LPE rate to the LPE rate at the shoreline. The absolute enhancement, AE, is the difference between the maximum LPE rate and the LPE rate at the shoreline. InDisp and AE are zero if the maximum LPE rate occurs at the shoreline.

\section{Wind direction}

The direction of $\bar{U}$ at GP1 during sea-effect periods utilized in this study is $260^{\circ}-340^{\circ}$ for $85 \%$ of the time, therefore to illustrate the general influence of wind direction, we examine sea-effect periods (hereafter periods) with a wind direction within $10^{\circ}$ of $270^{\circ}$, $290^{\circ}, 310^{\circ}$, and $330^{\circ}$ (Fig. 4). We focus on periods with $\bar{U}$ and SiCAPE between the 30th and 70th percentile (10.3-14.9 $\mathrm{m} \mathrm{s}^{-1}$ and $2062-2846 \mathrm{~J} \mathrm{~kg}^{-1}$, respectively). These thresholds were chosen because they represent moderate values of each variable, and they maintain a sample size within each wind direction comparable to other partitions presented later.
For a $270^{\circ}$ wind direction, the highest LPE rates extend eastward along the coast immediately north of the Kubiki Mountains, across the southern Echigo Plain, and into the central and northern Echigo Mountains (Fig. 4a). This elongated LPE maximum avoids the high terrain of the Hida, Kubiki, and southwest Echigo Mountains. Yoshihara et al. (2004) describe a similar precipitation pattern for a sea-effect event in the Hokuriku region under comparable nearzonal flow. They found that the low-level $(<1000 \mathrm{~m}$ MSL) flow was blocked on the western side of the Hida Mountains, resulting in a cold southwesterly flow from the interior converging with the large-scale zonal flow over Toyama Bay, intensifying precipitation. We hypothesize that such terrain effects lead to the elongated LPE rate pattern evident in Fig. 4a. Only in the northern Echigo Mountains, where the flow is oriented more normal to the terrain, do higher LPE rates extend into the mountains, though these LPE rates do not match those in the maximum across the southern Echigo Plain and foothills.

The Noto Peninsula and Sado Island also modulate precipitation. For example, a band of higher LPE rates extends downwind from the tip of the Noto Peninsula to the northern Echigo Plain. In contrast, weak shadowing exists downwind of the central Noto Peninsula and mountainous Sado Island. These modulations likely reflect the influence of the coastal geometry and terrain of the Noto Peninsula and Sado Island.

The LPE rate pattern for a $290^{\circ}$ wind direction is generally similar to that for $270^{\circ}$ with the highest LPE rates extending downstream from along the coast immediately north of the Kubiki Mountains, across the Echigo Plain, and into the central Echigo Mountains (Fig. 4b). However, there is a southward shift in the position of the LPE maximum over the Echigo Plain and an increase in LPE rate in the foothills of the southwest Echigo Mountains. Finally, the orientations of the band produced by the Noto Peninsula and shadowing downwind of the central Noto Peninsula and Sado Island rotate clockwise with the flow. The shadowing downwind of Sado Island is also more pronounced, reflecting the stronger cross-barrier flow component relative to the crest of the island terrain, and extends downstream across the northern and central Echigo Plain and Mountains.

For flows from $310^{\circ}$ and $330^{\circ}$, which in many areas yields a strong onshore and upslope component, LPE rates reach their highest values throughout most of the study region, with the rate at some sites an order of magnitude higher for $310^{\circ}$ flow compared to $270^{\circ}$ (Figs. 4c,d). LPE rates are highest over the windward slopes of the Hida and Kubiki Mountains, the 

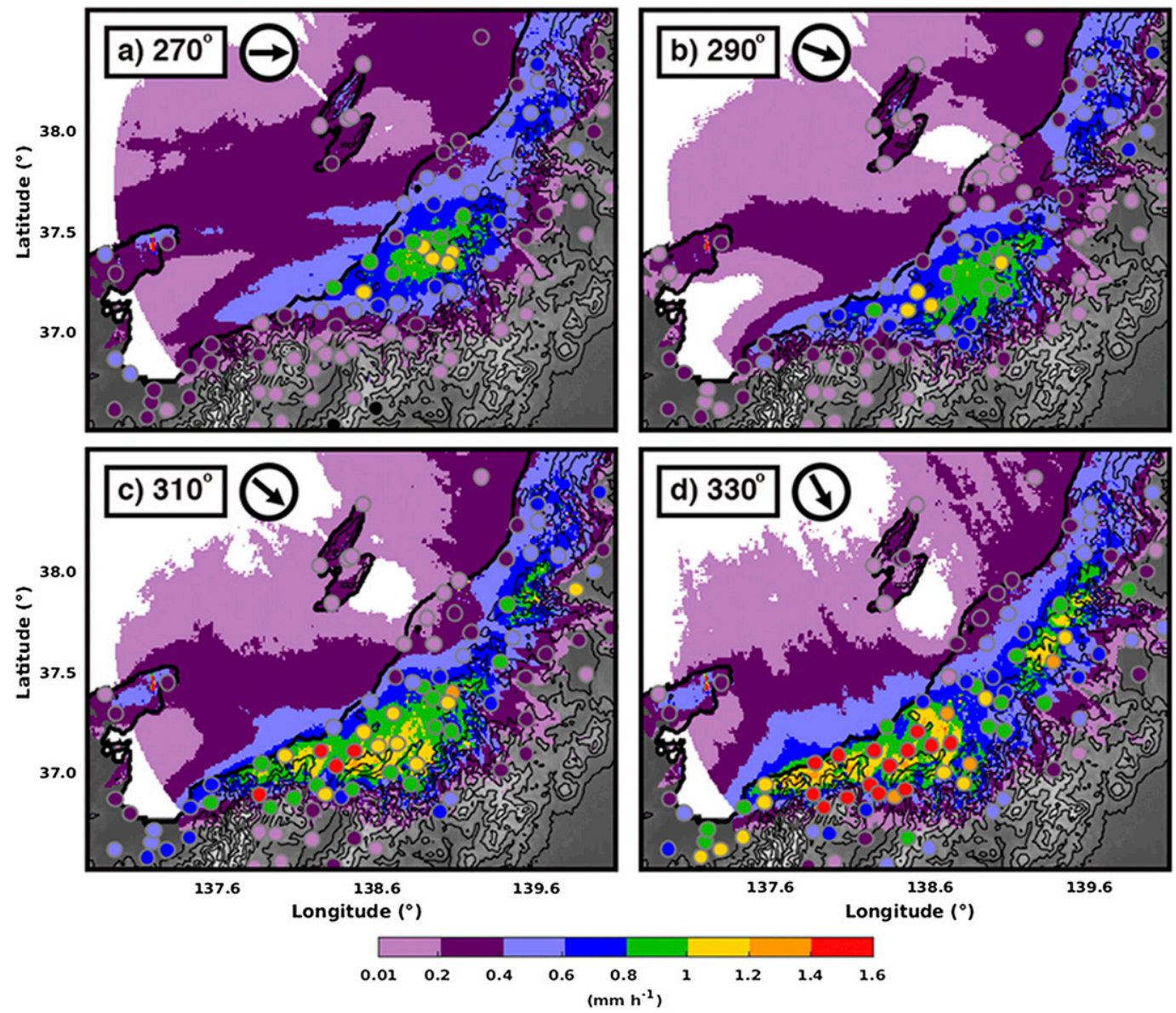

FIG. 4. Mean radar-derived LPE rate (color fill) and LPE rate at surface observing sites (colored dots) during seaeffect periods with a moderate $\bar{U}$, moderate SiCAPE, and a boundary layer wind direction aligned within $10^{\circ}$ of (a) $270^{\circ}$, (b) $290^{\circ}$, (c) $310^{\circ}$, and (d) $330^{\circ}$. Terrain elevation contours every $400 \mathrm{~m}$ MSL. There are $846,4148,1038$, and 228 YAHI scans and $141,692,173$, and 38 ERA5 analysis times in the $270^{\circ}, 290^{\circ}, 310^{\circ}$, and $330^{\circ}$ periods, respectively.

southwest Echigo Plain, and the adjoining foothills of the southwest Echigo Mountains. Although radar limitations exaggerate the decrease in LPE rates farther inland, gauge measurements confirm an eventual decline in LPE rate with inland extent, even over high terrain. The gauge measurements also suggest higher LPE rates within the LPE maximum than indicated by radar estimates. LPE rates increase sharply near the coast over a distance of $\sim 10 \mathrm{~km}$. This sharp gradient is present both where the Hida and Kubiki Mountains rise abruptly at the coast and over the relatively flat Echigo Plain. While the Hida and Kubiki mountains provide a possible lifting mechanism to support such a strong gradient, the forcing mechanism along the coast of the Echigo Plain is less clear. One possibility is mesoscale ascent along a coastal or landbreeze front separating relatively mild maritime air from cooler continental air over the Echigo Plain (e.g., Ohigashi and Tsuboki 2005; Campbell and Steenburgh 2017). Topographic blocking might also create a blocking front upstream of the topography (e.g., Neiman et al. 2002). Finally, the influences of the Noto Peninsula and Sado Island remain apparent. Shadowing in the lee of Sado Island, in particular, produces an LPE rate minimum that extends downstream across the central Echigo Plain and Mountains.

These results illustrate a strong dependency of the distribution and intensity of precipitation on wind direction in the Hokuriku region. During flow from the west (e.g., $270^{\circ}$ and $290^{\circ}$, Figs. 4a,b), banding along the coast north of the Hida and Kubiki Mountains may reflect low-level flow deflection by the Hida Mountains, which generates convergence near the coast. This banding extends into the southern Echigo Plain, where the maximum LPE rates occur at the foot of the southwest Echigo Mountains. In the central and northern Echigo Mountains, which are lower and oriented more normal to the flow, precipitation tends to extend farther inland into the high terrain, though LPE rates do not match those in the lowland maximum to 

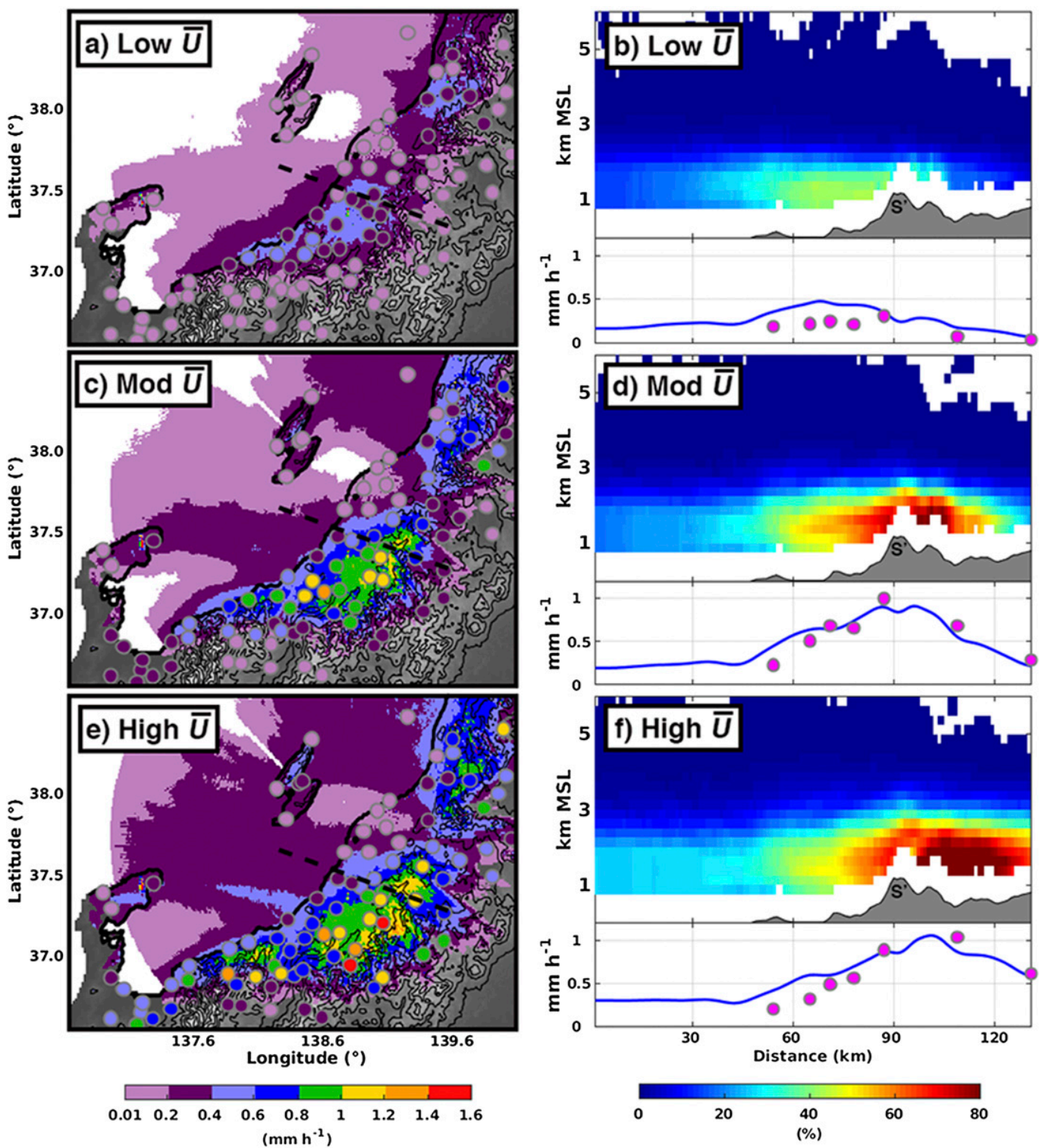

FIG. 5. Mean radar-derived LPE rate (color fill) and LPE rate at surface observing sites (colored dots) during seaeffect periods with a boundary layer wind direction aligned within $10^{\circ}$ of $290^{\circ}$ and (a) low $\bar{U}$, (c) moderate $\bar{U}$, and (e) high $\bar{U}$. Dashed line indicates position of T1. Terrain elevation contours every $400 \mathrm{~m}$ MSL. (right) (top) Frequency of echoes $\geq 10 \mathrm{~dB} Z$, mean radar-derived LPE rate along T1 (blue line; smoothed using an 8-point moving mean), and mean observed LPE rate from gauges within $10 \mathrm{~km}$ of T1 (magenta circles) during sea-effect periods with a boundary layer wind direction aligned within $10^{\circ}$ of $290^{\circ}$ and (b) low $\bar{U}$, (d) moderate $\bar{U}$, and (f) high $\bar{U}$. S' indicates the location of Mt. Sumon. There are 3652, 3652, and 3648 YAHI scans and 609, 609, and 608 ERA5 analysis times in the low, moderate, and high $\bar{U}$ periods, respectively.

the south. For flow from the NW (e.g., $310^{\circ}$ and $330^{\circ}$, Figs. $4 \mathrm{c}, \mathrm{d})$, there is a stronger onshore and cross-barrier flow component for the southern portion of the domain and precipitation rates are higher. The heaviest precipitation occurs over the windward slopes of the Hida and Kubiki Mountains, the southwest Echigo Plain, and the southwest Echigo Mountain foothills, but precipitation rates decrease farther inland, even over high terrain. The northern Echigo Mountains, which are generally lower than the ranges to the south and are oriented nearly flow normal for flow from $270^{\circ}$ to $330^{\circ}$, see similar LPE rates and enhancement for all of the flow directions in that range. These results are, however, for moderate $\bar{U}$ and SiCAPE values. Next we examine how $\bar{U}$ modulates the inland and orographic enhancement of precipitation for selected flow directions. 

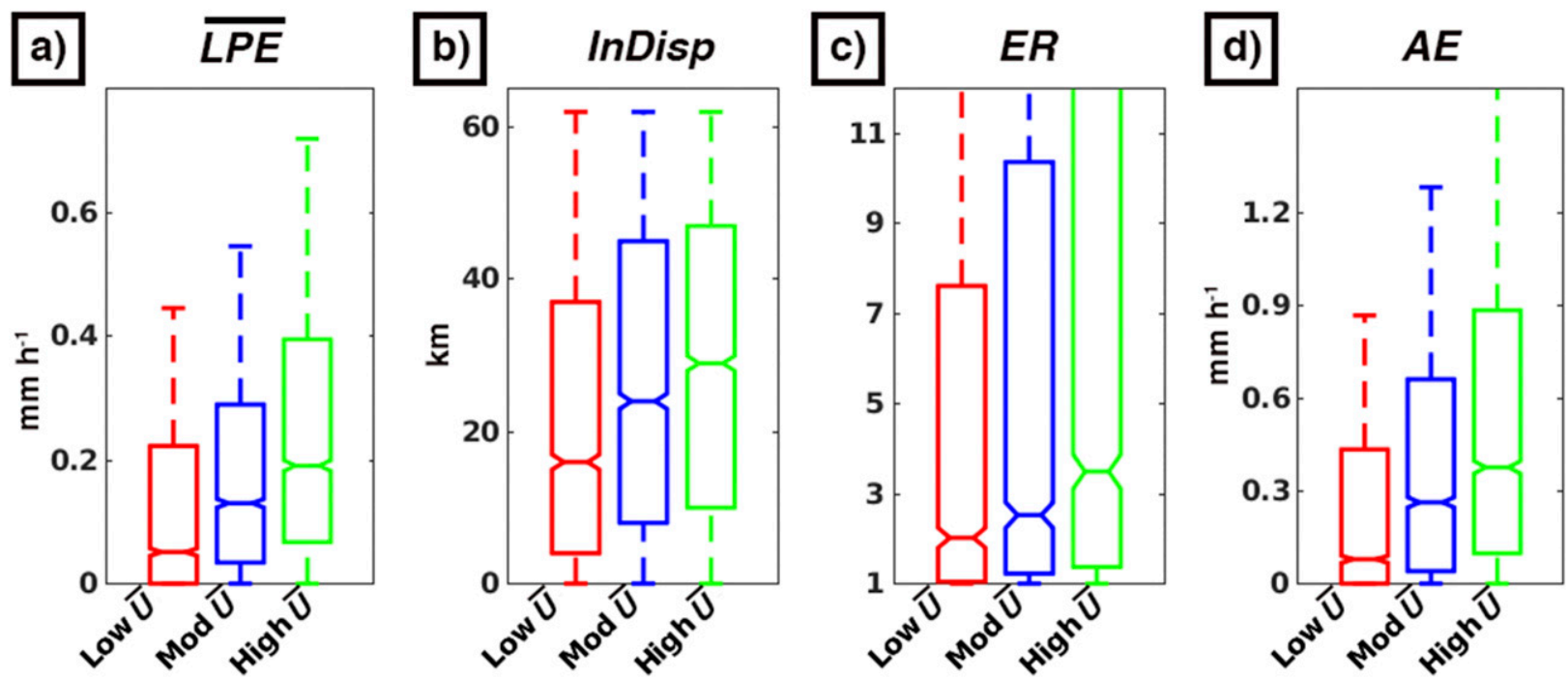

FIG. 6. Box-and-whisker plot of (a) $\overline{\mathrm{LPE}}$, (b) InDisp, (c) ER, and (d) AE along T1 corresponding to Fig. 5. The difference between the medians is statistically significant at the $95 \%$ confidence level if the notched areas around the respective medians do not overlap.

\section{4. $\bar{U}$}

To examine the influence of $\bar{U}$, we first consider periods with a wind direction within $10^{\circ}$ of $290^{\circ}$. We then divide $\bar{U}$ in these periods into quintiles, with the lower (0th-20th percentile; $\leq 8.8 \mathrm{~m} \mathrm{~s}^{-1}$ ), middle (40th-60th percentile; $11.5-13.6 \mathrm{~m} \mathrm{~s}^{-1}$ ), and upper (80th-100th percentile; $\geq 16.4 \mathrm{~m} \mathrm{~s}^{-1}$ ) quintiles referred to hereafter as low, moderate, and high $\bar{U}$.

Low $\bar{U}$ periods feature relatively low LPE rates, with the highest values confined to the Echigo Plain and lower windward slopes of the Echigo Mountains, as illustrated by plan-view analysis (Fig. 5a) and transect T1 (Fig. 5b). Radar echoes $\geq 10 \mathrm{~dB} Z$ are shallow and most frequent over the Echigo Plain and lower windward slopes of the Echigo Mountains (Fig. 5b). Under moderate $\bar{U}$, the LPE rates increase with the maximum shifting inland to Mt. Sumon (Figs. 5c,d). Radar echoes $\geq 10 \mathrm{~dB} Z$ are most frequent and deepen over and in the vicinity of this peak (Fig. 5d). During high $\bar{U}$ periods the LPE rates increase throughout much of the study region and the precipitation maximum shifts farther inland (Fig. 5e). Along T1, the LPE maximum and highest frequency of $\geq 10-\mathrm{dB} Z$ radar echoes shift downstream of Mt. Sumon (Fig. 5f, note that the YAHI radar is fortuitously located to enable low-level scanning on both sides of Mt. Sumon), but over the southwest Echigo Mountains, which are higher and oriented less normal to a $290^{\circ}$ flow, the LPE maximum remains upwind of the highest terrain (Fig. 5e). For all values of $\bar{U}$, the influence of the Noto Peninsula and Sado Island are apparent, with a band of higher LPE rates extending downwind from the former into the Echigo Plain and shadowing extending downwind from the latter into the northern Echigo Mountains (Figs. 5a,c,e).

Box-and-whisker plots of quantitative variables for individual radar scans along T1 show a statistically significant increase in LPE [statistical significance here and elsewhere based on a 95\% confidence level, utilizing the method of McGill et al. (1978) via the MATLAB software] as $\bar{U}$ increases from low to moderate to high values (Fig. 6a). InDisp increases at a statistically significant level with increasing $\bar{U}$, indicating the propensity for the LPE maximum to shift farther inland as $\bar{U}$ increases (Fig. 6b). ER and AE also increase with $\bar{U}$ at statistically significant levels, indicating a strong correlation of the inland and orographic enhancement of LPE with $\bar{U}$ (Figs. 6c,d).

We next examine wind directions within $10^{\circ}$ of $320^{\circ}$, which is intermediate to the $310^{\circ}$ and $330^{\circ}$ flow directions presented in Figs. $4 \mathrm{c}$ and $4 \mathrm{~d}$ and oriented more normal to the southwest Echigo Mountains. Similarly, we divide $\bar{U}$ into lower $\left(\leq 5.0 \mathrm{~m} \mathrm{~s}^{-1}\right)$, middle (7.1$\left.9.5 \mathrm{~m} \mathrm{~s}^{-1}\right)$, and upper $\left(\geq 11.9 \mathrm{~m} \mathrm{~s}^{-1}\right)$ quintiles, referred to hereafter as low, moderate, and high $\bar{U}$. Note that as a result of the climatology of $320^{\circ}$ flow, these values are lower than the low, moderate, and high values for a $290^{\circ}$ flow. Low $\bar{U}$ periods feature an LPE maximum located near the coast or slightly offshore, with little precipitation at sites farther inland (Fig. 7a). The flow-parallel transect, T2, shows an inland decline in LPE rates and frequency of radar echoes $\geq 10 \mathrm{~dB} Z$, with a shallow maximum in the former near the coast (Fig. 7b). Moderate $\bar{U}$ results in higher LPE rates throughout the domain, with a sharp gradient at 

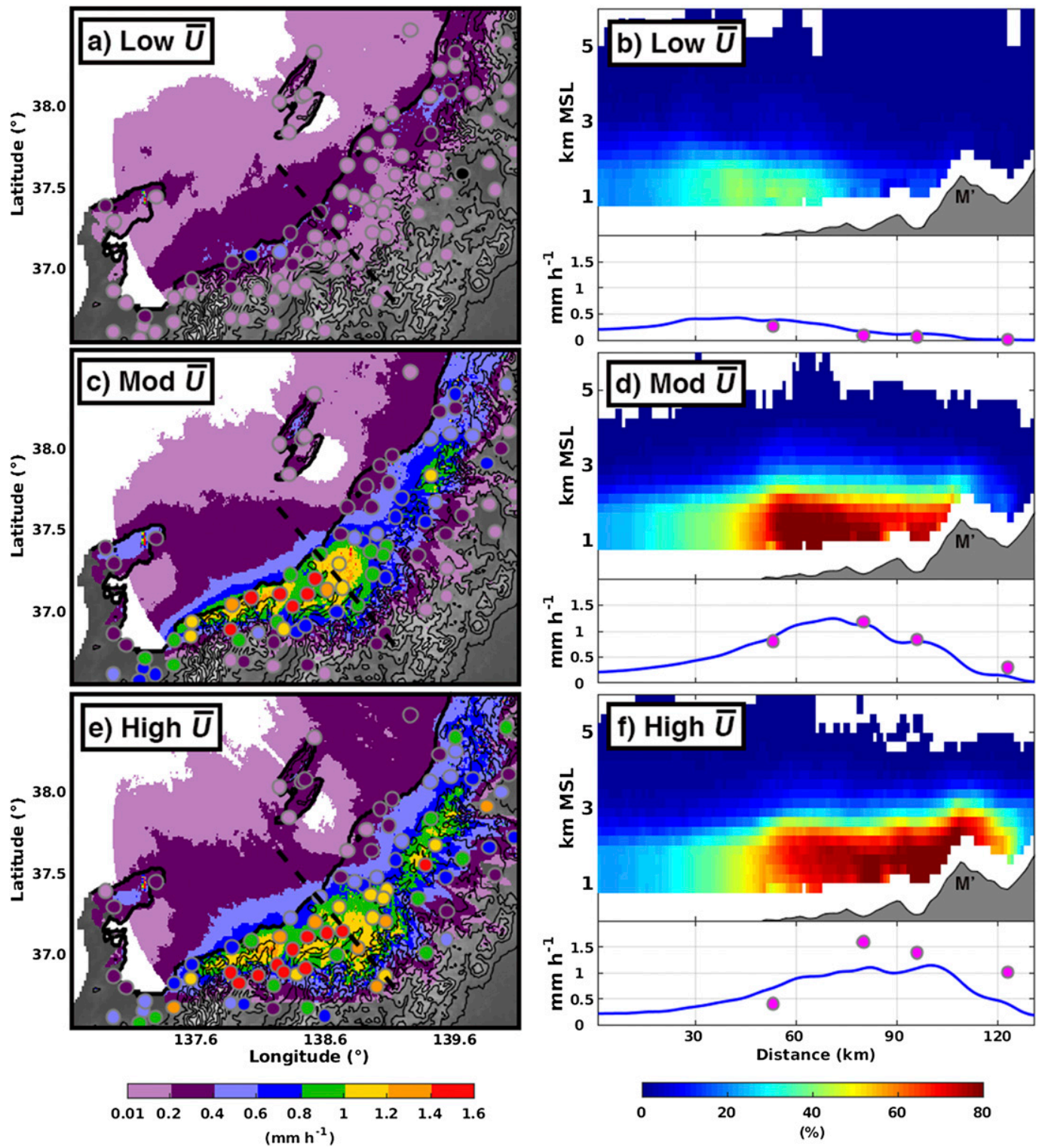

FIG. 7. As in Fig. 5, but during sea-effect periods when $\bar{U}$ is aligned within $10^{\circ}$ of $320^{\circ}$ and transect is T2. M' indicates the location of Mt. Makihata. There are 663, 665, and 659 YAHI scans and 111, 111, and 110 ERA5 analysis times in the low, moderate, and high $\bar{U}$ periods, respectively.

the coast and heavy precipitation over the windward slopes of the Hida and Kubiki Mountains, the southwest Echigo Plain, and the southwest Echigo Mountain foothills (Fig. 7c). The frequency of echoes $\geq 10 \mathrm{~dB} Z$ along $\mathrm{T} 2$ shows a dramatic increase in echo frequency over the Echigo Plain and southwest Echigo Mountain foothills (Fig. 7d). LPE rates and the frequency of radar echoes $\geq 10 \mathrm{dBZ}$ maximize over the plain and foothills and decrease farther inland, especially across Mt. Makihata (Fig. 7d). High $\bar{U}$ periods shift the precipitation farther inland to the windward slopes of Mt. Makihata, though LPE rates remain relatively high throughout the transect (Figs. 7e,f). Although there is an increase in spillover across Mt. Makihata, LPE rates eventually decline farther inland, even over high terrain, which may reflect a decay in sea-effect storm dynamics or the depletion of water mass by precipitation with inland extent (e.g., Minder et al. 2015; Eipper et al. 2018). This decline is exaggerated in radar-estimated LPE rates, but it is confirmed by gauge measurements. Box-and-whisker plots of quantitative variables for individual radar scans along T2 are similar to those in Fig. 6 for T1, and thus are not shown. 

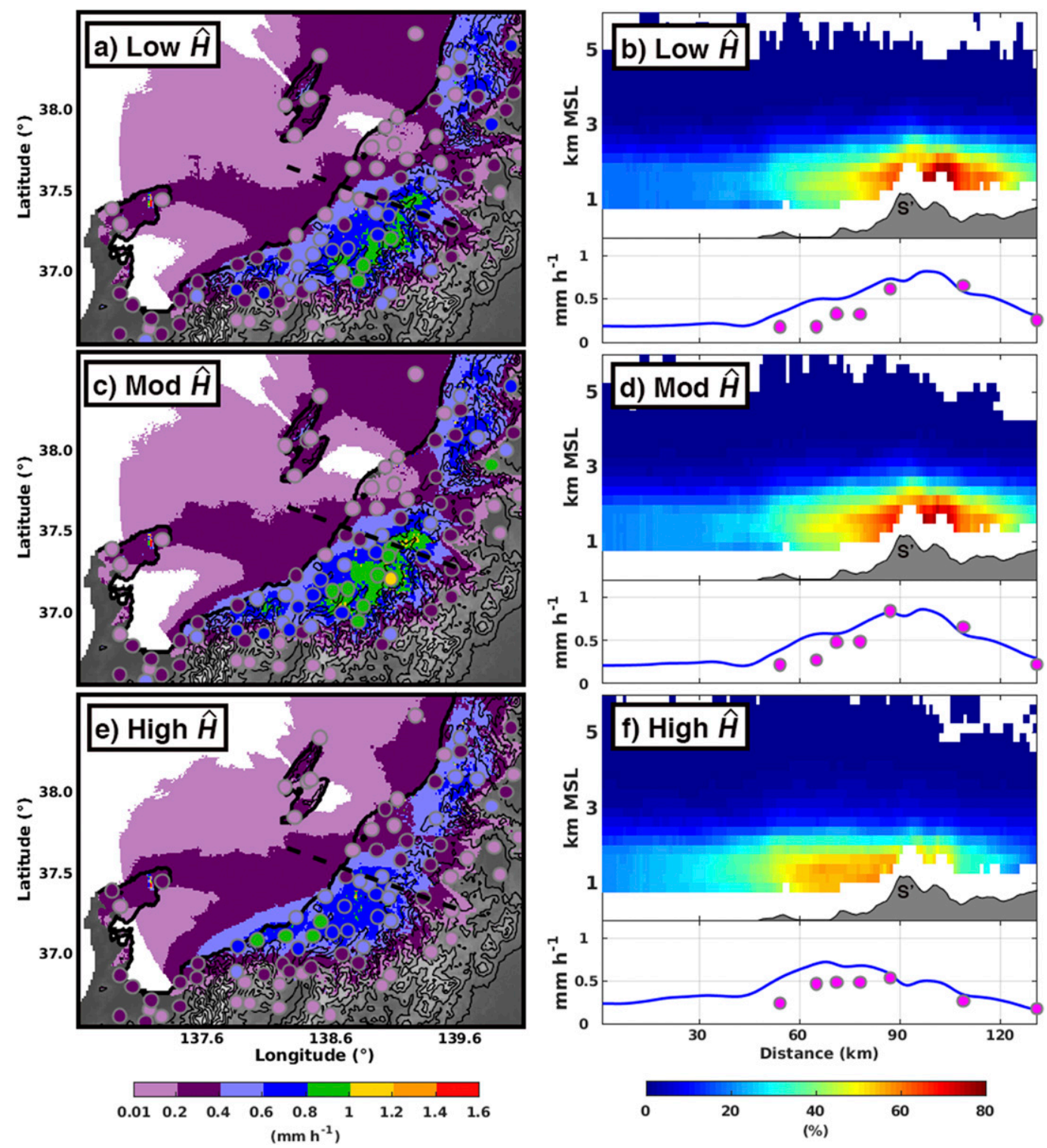

FIG. 8. As in Fig. 5, but for (a),(b) low, (c),(d) moderate, and (e),(f) high $\hat{H}$. There are 3794, 3635, and 3559 YAHI scans and 632, 606, and 594 ERA5 analysis times in the low, moderate, and high $\hat{H}$ periods, respectively.

These results illustrate that $\bar{U}$ modulates the mean LPE rate along the transects, the location of the LPE maximum, and the enhancement relative to the shoreline. There is, however an eventual inland decline in LPE rate even over high terrain and for high $\bar{U}$.

\section{5. $\hat{H}$}

$\hat{H}$ is dependent upon $\bar{U}$, but as discussed in section 2, provides a quantification of the terrain-induced flow behavior by accounting for barrier height, the strength of the barrier-normal flow, and the static stability of the impinging air mass. As with $\bar{U}$, the values of $\hat{H}$ during periods with a $290^{\circ}$ wind direction were divided into quintiles, with the lower $(\leq 0.46)$, middle $(0.59-0.74)$, and upper $(\geq 1.03)$ quintiles referred to as low, moderate, and high $\hat{H}$, respectively. This assumes $h=1500 \mathrm{~m}$, the height of Mt. Sumon.

As one might expect with $\hat{H} \leq 0.46$ and a propensity for flow to move over terrain, low $\hat{H}$ periods feature LPE rates that increase from the shoreline to the mountains, reaching a maximum just downstream of Mt. Sumon (Figs. 8a,b). Similarly, the frequency of radar echoes $\geq 10 \mathrm{~dB} Z$ maximizes near and downstream of Mt. Sumon. Moderate $\hat{H}$ periods, also with $\hat{H}$ values consistent with flow over terrain, feature a 

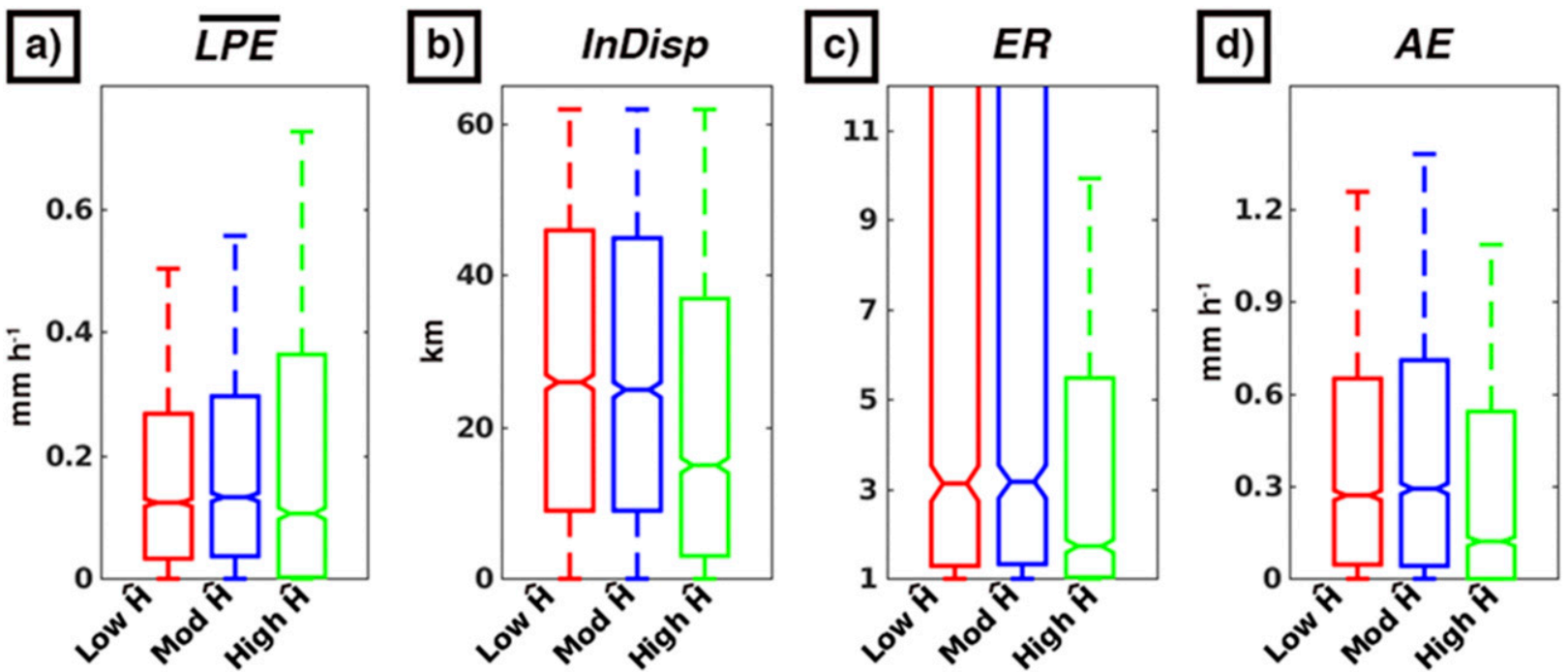

FIG. 9. Box-and-whisker plot of (a) LPE, (b) InDisp, (c) ER, and (d) AE along T1 corresponding to Fig. 8. The difference between the medians is statistically significant at the $95 \%$ confidence level if the notched areas around the respective medians do not overlap.

similar distribution, with a small increase in LPE rate and $\geq 10-\mathrm{dB} Z$ echo frequency upwind of Mt. Sumon and corresponding decreases in the lee (Figs. 8c,d). The shift to high $\hat{H}$, which would be associated with greater flow deceleration and in some instances blocking since this includes periods with $\hat{H} \geq 1.03$, brings a more drastic change (although caution must be used in such a comparison with a formula of $\hat{H}$ neglecting the effects of moisture). LPE rates and echo frequencies $\geq 10 \mathrm{~dB} Z$ weaken in general and exhibit maxima over the Echigo Plain rather than over or near Mt. Sumon, and echoes also no longer tend to deepen with inland extent (Figs. 8e,f). Thus, increased flow deceleration and blocking shift the precipitation upstream, as observed in other regions, such as the California coastal mountains and European Alps (e.g., Neiman et al. 2002; Rotunno and Houze 2007; Hughes et al. 2009).

Examining the quantitative variables along T1, $\overline{\mathrm{LPE}}$ exhibits no statistically significant change between low and moderate $\hat{H}$, but decreases for high $\hat{H}$ periods (Fig. 9a), suggesting that $\hat{H}$ does not strongly affect the overall LPE intensity until $\hat{H}>1$. InDisp is highest for low $\hat{H}$, similar for moderate $\hat{H}$, and then dramatically lower for high $\hat{H}$ (Fig. 9b). For ER and AE, there is no statistically significant difference between low $\hat{H}$ and moderate $\hat{H}$ periods, but a large, statistically significant decrease for high $\hat{H}$ (Figs. 9c,d). These results generally agree with theoretical expectations (e.g., Pierrehumbert and Wyman 1985; Smith 1988; Colle 2004; Galewsky 2008), with precipitation rates in the mountains greatest for $\hat{H} \ll 1$, and an upstream shift in precipitation and decrease in mountain precipitation for $\hat{H} \gtrsim 1$.
We next examine the effects of $\hat{H}$ for events with a $320^{\circ}$ wind direction with $\hat{H}$ similarly divided into lower ( $\leq 1.05)$, middle (1.47-2.14), and upper ( $\geq 4.01)$ quintiles, referred to hereafter as low, moderate, and high $\hat{H}$. This assumes $h=2000 \mathrm{~m}$, the height of Mt. Makihata. These values are higher than those of $\mathrm{T} 1$, reflecting the lower values of $\bar{U}$ for a $320^{\circ}$ wind direction and greater terrain heights along $\mathrm{T} 2$.

Low $\hat{H}$ periods feature an increase in LPE rate at the coast with the highest LPE rates over southwest Echigo Mountains foothills (Fig. 10a). This can be seen along T2 with the maximum LPE rates just windward of Mt. Makihata (Fig. 10b). Although radar estimated precipitation and the frequency of radar echoes $\geq 10 \mathrm{~dB} Z$ declines in the lee, gauge measurements indicate a less abrupt transition with significant spillover across Mt. Makihata. The LPE rate maximum strengthens and shifts upstream during moderate $\hat{H}$ periods, with a stronger gradient in LPE rate and frequency of radar echoes $\geq 10 \mathrm{dBZ}$ at the coastline and precipitation declining near and over Mt. Makihata (Figs. 10c,d). For high $\hat{H}$, the maximum weakens and moves farther upstream, with echoes confined mainly to areas near and off the coast and almost no LPE or radar echoes over Mt. Makihata and the southwest Echigo Mountains (Figs. 10e,f). Box-and-whisker plots of quantitative variables for individual radar scans along T2 agree well with the analysis above for Fig. 10, and are not shown.

Thus, the results for a $320^{\circ}$ wind direction are also consistent with theoretical expectations with precipitation shifting upstream with increasing $\hat{H}$. However, along $\mathrm{T} 2$ even the low $\hat{H}$ quintile exhibits radar-derived 

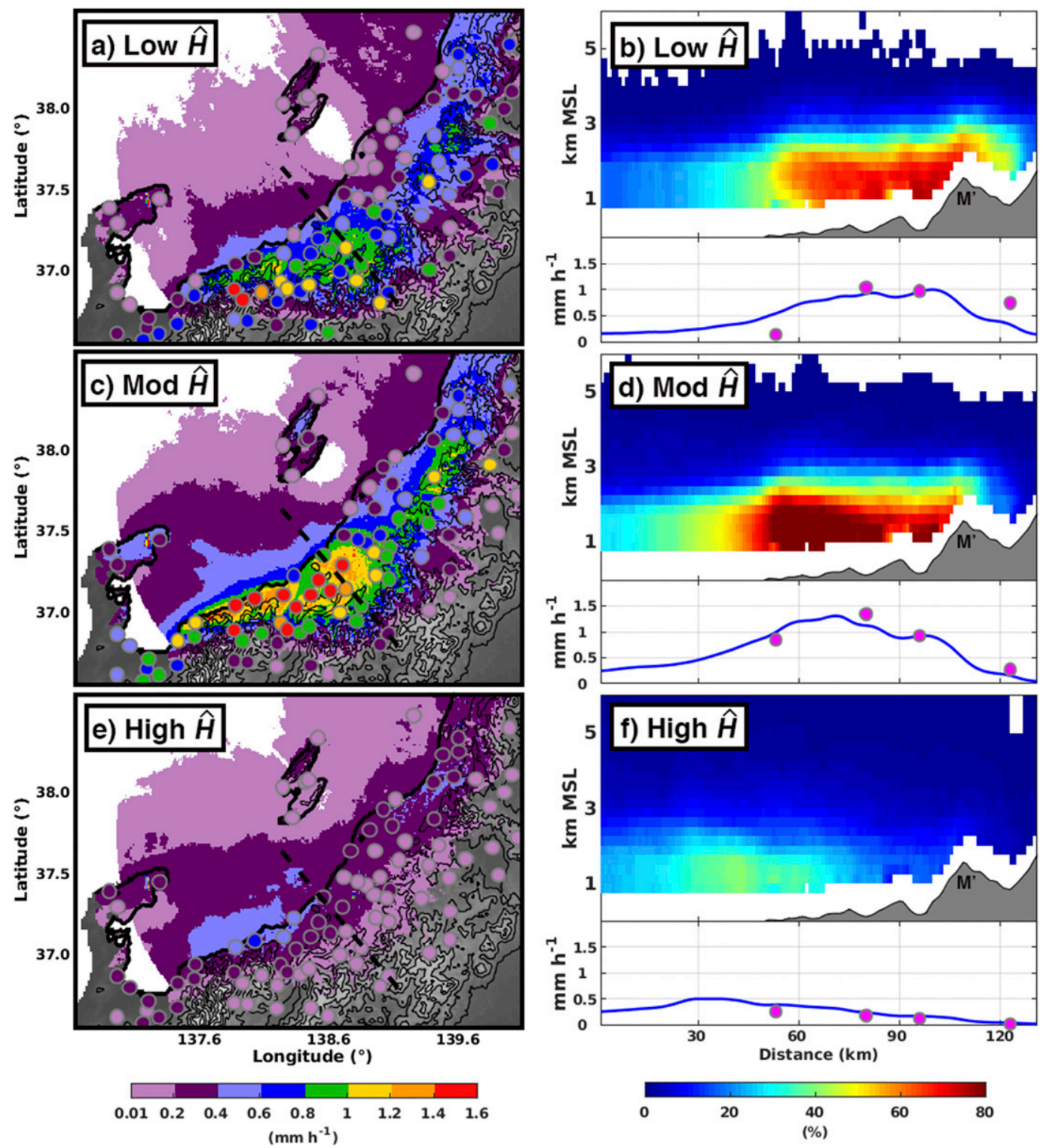

FIG. 10. As in Fig. 7, but for (a),(b) low, (c),(d) moderate, and (e),(f) high $\hat{H}$ events. There are 676, 666, and 644 YAHI scans and 113,111, and 108 ERA5 analysis times in the low, moderate, and high $\hat{H}$ periods, respectively.

LPE and frequency of radar echoes $\geq 10$-dB $Z$ maxima over and upwind of the windward slopes of Mt. Makihata rather than over the crest. Although the gauge measurements show a less dramatic decline across Mt. Makihata, they are still consistent with a maximum windward of the peak. This reflects the higher terrain and tendency for lower $\bar{U}$ along this flow direction, which yields an $\hat{H}$ distribution shifted toward higher values.

\section{SiCAPE}

As with the preceding variables, SiCAPE is divided into low $\left(\leq 1836 \mathrm{~J} \mathrm{~kg}^{-1}\right)$, moderate $\left(2260-2629 \mathrm{~J} \mathrm{~kg}^{-1}\right)$, and high $\left(\geq 3115 \mathrm{~J} \mathrm{~kg}^{-1}\right)$ quintiles for periods with $290^{\circ}$ flow. Low SiCAPE periods feature relatively low LPE rates, with a broad maximum over the Echigo Plain and adjacent mountains (Fig. 11a). Along T1, the frequency of $10-\mathrm{dB} Z$ echoes is greatest near Mt. Sumon (Fig. 11b). Although the distribution is skewed toward the Echigo Plain and windward slopes of Mt. Sumon, precipitation rates in the lee are not dramatically lower. For moderate SiCAPE, the LPE rates increase across most of the region and throughout the transect, with echoes tending to be slightly deeper, but the distribution between the lowland and upland areas changes little (Figs. 11c,d). During high SiCAPE periods, LPE rates increase further 

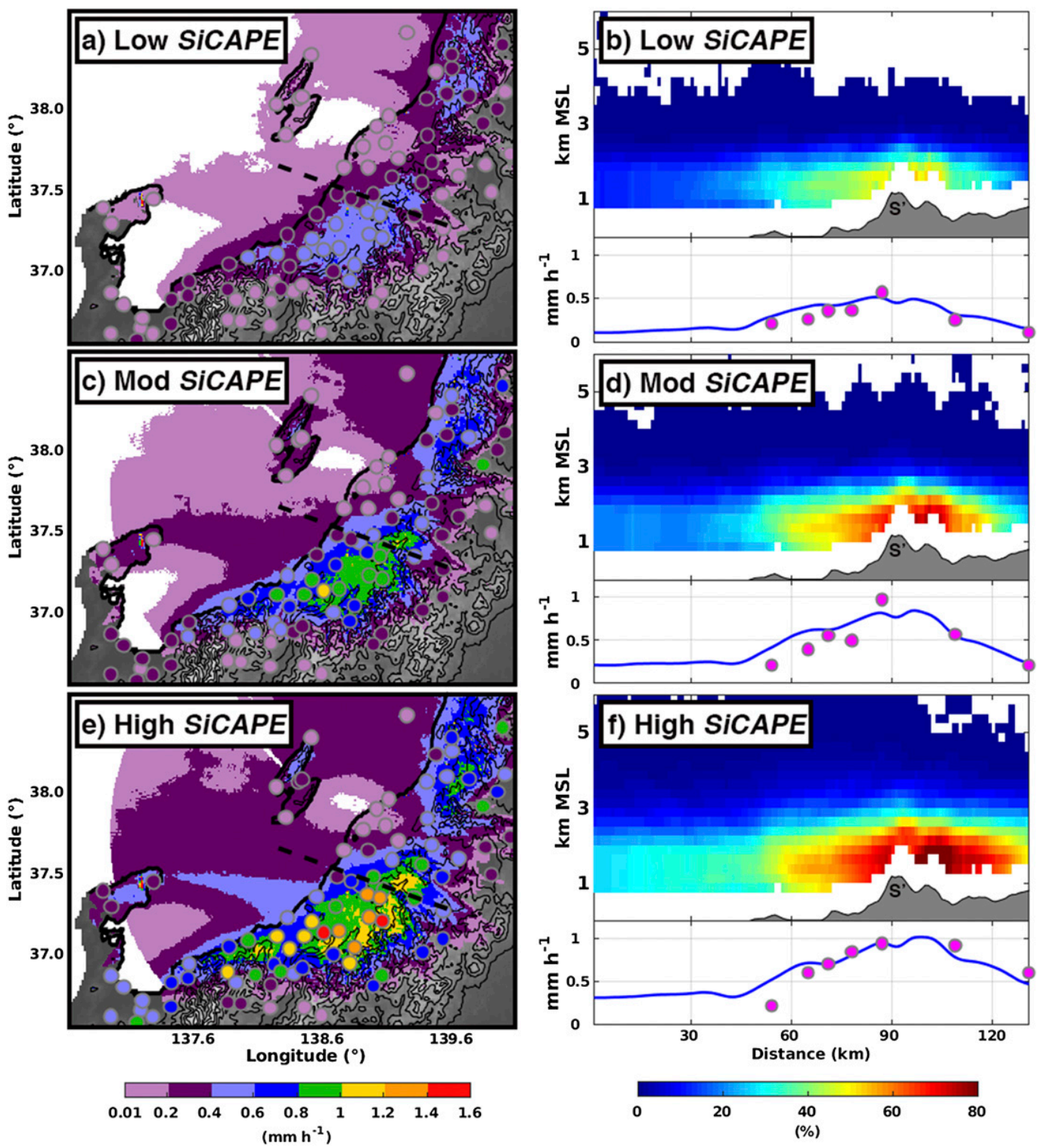

FIG. 11. As in Fig. 5, but for (a),(b) low, (c),(d) moderate, and (e),(f) high SiCAPE. There are 3651, 3652, and 3650 YAHI scans and 609, 609, and 609 ERA5 analysis times in the low, moderate, and high SiCAPE periods, respectively.

still, and deeper echo tops become more frequent, consistent with increased frequency and intensity of precipitation, and likely also indicative of more convection over the SOJ (Figs. 11e,f). However, the overall pattern remains fairly similar, although there is a slight downstream shift of the radar-estimated and gauge-measured precipitation maximum to the lee of Mt. Sumon.

Quantifying these effects, $\overline{\mathrm{LPE}}$ increases at a statistically significant level with increasing SiCAPE (Fig. 12a). InDisp increases as SiCAPE increases from low to moderate, but there is no statistically significant change from moderate to high (Fig. 12b). ER increases from low to moderate SiCAPE, but not by a statistically significant amount between moderate and high periods (Fig. 12c). AE is well correlated with SiCAPE, exhibiting a statistically significant increase between each level (Fig. 12d). Therefore SiCAPE appears to strongly affect the intensity of seaeffect precipitation, with trends in InDisp and ER suggesting a slightly lesser influence on inland and orographic enhancement than that observed for $\bar{U}$.

The analysis for $320^{\circ}$ flow yields similar results, although the effects of SiCAPE on LPE rate are even more pronounced. Low SiCAPE periods feature low LPE rates, with echoes shallow and confined mainly 

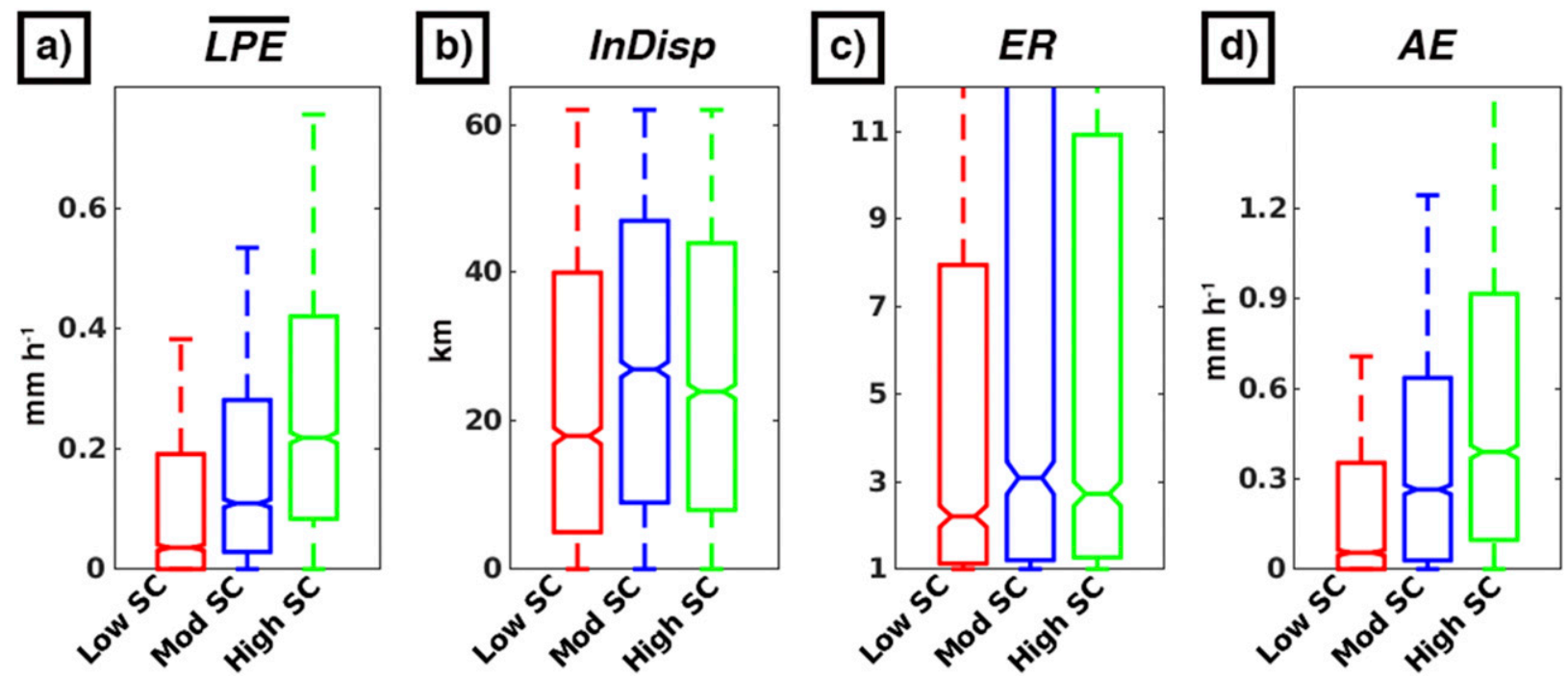

FIG. 12. Box-and-whisker plot of (a) $\overline{\mathrm{LPE}}$, (b) InDisp, (c) ER, and (d) AE along T1 corresponding to Fig. 11. The difference between the medians is statistically significant at the $95 \%$ confidence level if the notched areas around the respective medians do not overlap.

near the shoreline and Echigo Plain, well upstream of the southwest Echigo Mountains (Figs. 13a,b). The increase to moderate SiCAPE brings a large increase in LPE rates over the region and deeper echoes that penetrate farther inland (Figs. 13c,d). There is an inland shift of the LPE maximum, but it remains upstream of Mt. Makihata. High SiCAPE periods feature even larger LPE rates and deeper echoes, but the maximum remains upstream of Mt. Makihata (Figs. 13e,f). These results further highlight that SiCAPE strongly influences the intensity of sea-effect precipitation, with a slightly lesser influence on the inland and orographic enhancement than that observed for $\bar{U}$.

\section{Combined influence of $\bar{U}$ and SCAPE}

$\bar{U}$ and SiCAPE both strongly modulate the distribution and enhancement of LPE, and V18 found each to have distinct and important effects. Therefore following V18, we divide periods into low $\bar{U}$ (0th-40th percentile), high $\bar{U}$ (60th-100th percentile), low SiCAPE (0th-40th percentile), and high SiCAPE (60th-100th percentile). The 4 resulting combinations are thus:

1) Low $\bar{U} /$ Low SiCAPE (L $\bar{U} / \mathrm{LS})$

2) Low $\bar{U} / \mathrm{High} \mathrm{SiCAPE}$ (L $\bar{U} / \mathrm{HS})$

3) High $\bar{U} /$ Low SiCAPE (H $\bar{U} / \mathrm{LS})$

4) High $\bar{U} / \mathrm{High}$ SiCAPE (H $\bar{U} / \mathrm{HS})$

When evaluated with this multivariate approach, the influence of SiCAPE on lowland precipitation rate, and $\bar{U}$ on inland penetration and orographic enhancement, become apparent. L $\bar{U} / \mathrm{LS}$ periods feature relatively low
LPE rates, with most precipitation confined to the foothills and the coastal plain (Figs. 14a,b). For L $\bar{U} / \mathrm{HS}$ periods, the LPE rates increase and the echoes along the transect deepen slightly (Figs. 14c,d). However, the broad LPE maximum remains over the Echigo Plain and foothills, windward of Mt. Sumon. H $\bar{U} / \mathrm{LS}$ periods have similar lowland LPE rates to $\mathrm{L} \bar{U} / \mathrm{LS}$ and $\mathrm{L} \bar{U} / \mathrm{HS}$, but increased LPE rates over the mountains, with a maximum in LPE rate and frequency of 10-dBZ echoes just downwind of Mt Sumon (Figs. 14e,f). This is consistent with the expectations of greater inland penetration and orographic enhancement with increasing flow. For $\mathrm{H} \bar{U} / \mathrm{HS}$, the LPE rates increase throughout most of the region, with the overall pattern and distribution relatively unchanged (Figs. 14g,h). Along T1, echoes tend to be slightly deeper and the LPE maximum becomes pronounced in the lee of the crest (Fig. 14h).

Quantifying this, $\overline{\mathrm{LPE}}$ increases at a statistically significant level for increases in $\bar{U}$ and increases in SiCAPE (Fig. 15a). There is also a statistically significant increase in InDisp for increases in $\bar{U}$, with SiCAPE having a lesser effect (Fig. 15b). ER increases slightly for increases in $\bar{U}$ and SiCAPE and the $\mathrm{H} \bar{U}$ distributions extend to much higher values, but the only significant comparisons are between the two ends of the spectrum, $\mathrm{L} \bar{U} / \mathrm{LS}$ to $\mathrm{H} \bar{U} / \mathrm{HS}$ (Fig. 15c). AE increases at a statistically significant level for increases in $\bar{U}$ and SiCAPE (Fig. 15d). Thus, increased SiCAPE generally increases the inland and orographic enhancement independent of $\bar{U}$, although $\bar{U}$ appears to have the stronger effect.

The combination of $\hat{H}$ and SiCAPE yielded smaller contrasts than those of $\bar{U}$ and SiCAPE (not shown). We hypothesize that this is because $\bar{U}$ has multifaceted 

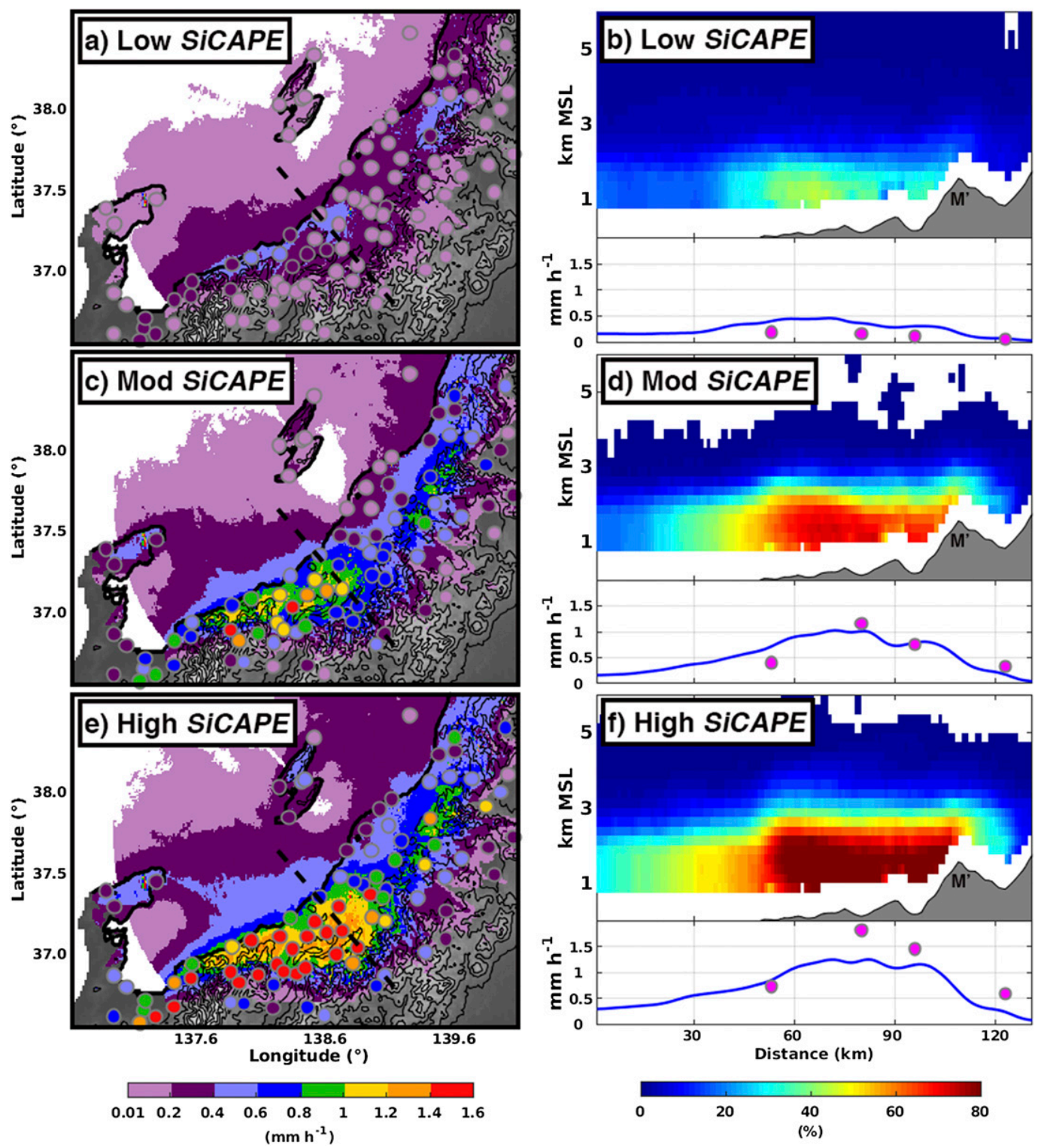

FIG. 13. As in Fig. 7, but for low (a),(b), moderate (c),(d), and high (e),(f) SiCAPE. There are 662, 660, and 659 YAHI scans and 111, 110, and 110 ERA5 analysis times in the low, moderate, and high SiCAPE periods, respectively.

influences on sea-effect precipitation, affecting the intensity of sea-effect convection by increasing sensible and latent heat fluxes, the inland penetration of sea-effect precipitation, and orographic effects. While $\hat{H}$ also plays a role in the latter, $\bar{U}$ is a better integrator of both the sea-effect precipitation and the orographic precipitation.

\section{Summary and conclusions}

This study has examined the factors affecting the inland and orographic enhancement of precipitation during sea-effect periods in the Hokuriku region of Japan. The effects of wind direction, $\bar{U}, \hat{H}$, and SiCAPE upon the distribution of precipitation were evaluated for sea-effect periods during the 9 cool seasons (December-February) from December 2007 through February 2016.

The mean LPE rate at many locations in the region can change by as much as an order of magnitude with a $40^{\circ}$ change in wind direction, with the most dramatic changes occurring at sites that are near or in high terrain, which can suppress precipitation or enhance it vigorously, depending on the flow direction. A wind direction oriented obliquely to the bulk of the high 

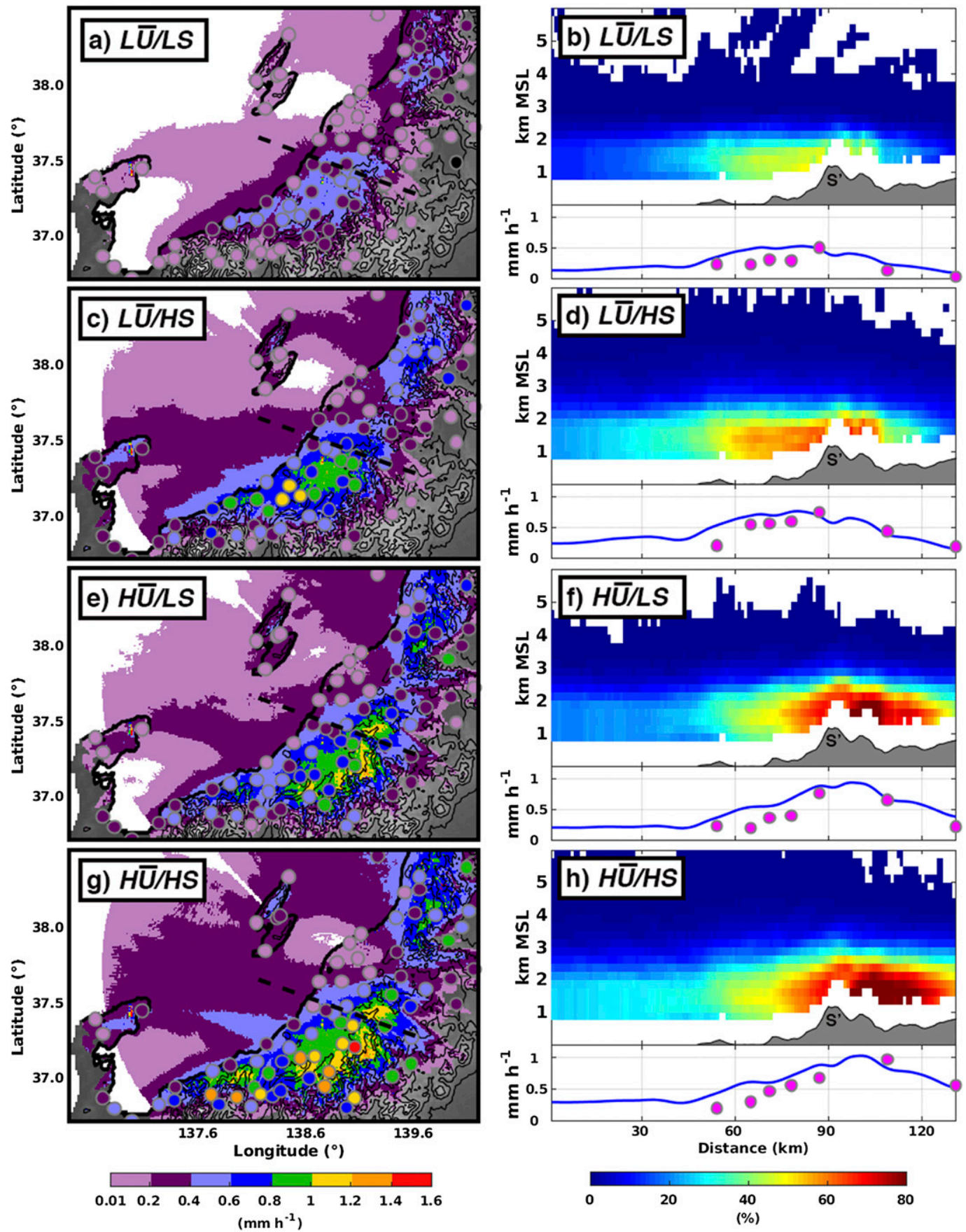

FIG. 14. As in Fig. 5, but for (a),(b) low $\bar{U} /$ low SiCAPE, (c),(d) low $\bar{U} /$ high SiCAPE, (e),(f) high $\bar{U} /$ low SiCAPE, and $(\mathrm{g}),(\mathrm{h})$ high $\bar{U} /$ high SiCAPE. There are 4489, 1532, 1283, and 4345 YAHI scans and 749, 256, 214, and 724 ERA5 analysis times in the $\mathrm{L} \bar{U} / \mathrm{LS}, \mathrm{L} \bar{U} / \mathrm{HS}, \mathrm{H} \bar{U} / \mathrm{LS}$ and $\mathrm{H} \bar{U} / \mathrm{HS}$ periods, respectively.

terrain in the region generally favors flow deflection around the higher elevation areas, relatively little LPE throughout the domain, and a maximum in the lowlands along the barrier. A wind direction oriented more orthogonal to the bulk of the high terrain generally favors flow over the barrier, relatively high LPE throughout the domain. Wind direction also affects LPE distribution in the coastal lowlands via the location of shadowing by Sado Island or banding in the lee of the Noto Peninsula, which can decrease or increase LPE rates, respectively.

Within a given wind direction, $\bar{U}$ and SiCAPE also have a definitive effect upon the LPE distribution, with 


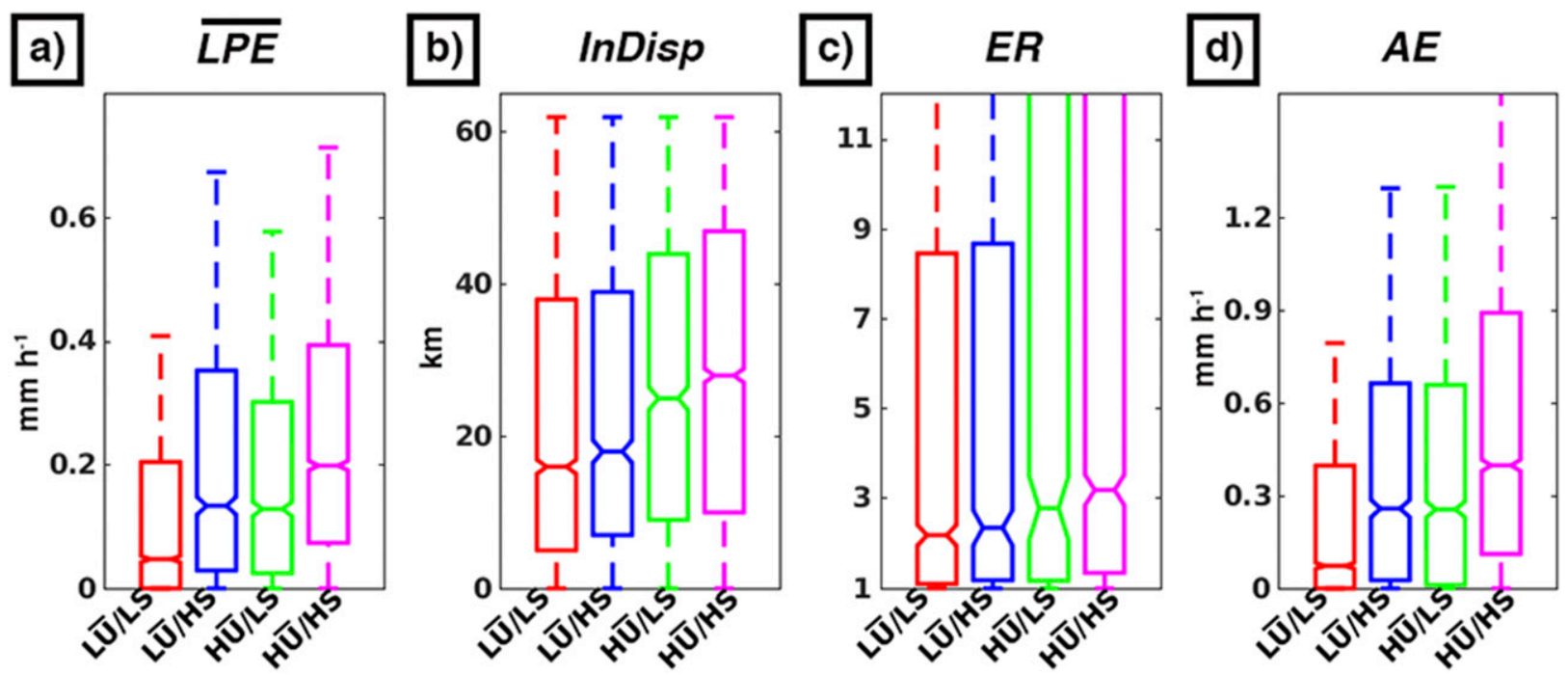

FIG. 15. Box-and-whisker plot of (a) $\overline{\mathrm{LPE}}$, (b) InDisp, (c) ER, and (d) AE along T1 corresponding to Fig. 14. The difference between the medians is statistically significant at the $95 \%$ confidence level if the notched areas around the respective medians do not overlap.

higher $\bar{U}$ favoring higher LPE rates throughout the domain, a maximum farther inland and higher in elevation, and a greater degree of LPE enhancement. Increasing SiCAPE is associated with higher LPE rates throughout the domain, an LPE maximum displaced farther inland, and slightly higher degree of LPE enhancement over the terrain. Though both variables strongly affect the LPE rate throughout the domain, the effect of $\bar{U}$ is stronger than that of SiCAPE upon the inland displacement and degree of enhancement. Similar results were found over Tug Hill downstream of Lake Ontario by V18, though the effect of LCAPE there is more complicated than that of SiCAPE in the Hokuriku region.

$\hat{H}$ proved to be a useful indicator of flow behavior, with effects upon the LPE distribution consistent with theoretical expectations. Periods with $\hat{H}<1$ feature an LPE maximum over the high elevations and a greater degree of LPE enhancement, with $\hat{H}>1$ having the opposite effect. There is an important distinction between the effects of $\bar{U}$ and $\hat{H}$ (which is inversely dependent upon $\bar{U}$ ) during sea-effect periods. Lower values of $\hat{H}$ increase the inland and orographic enhancement by allowing flow to surmount the barrier instead of being blocked or deflected. Higher values of $\bar{U}$, in addition to the effects of lower $\hat{H}$, also increase the LPE rates throughout the study region, including out over the water, potentially due to factors such as a corresponding increase in latent and sensible heat fluxes or the upslope moisture flux. Thus $\bar{U}$ is likely an effective integrator of multiple seaeffect and orographic processes that affect the distribution and intensity of LPE in the region. These distinct effects upon the distribution and intensity of LPE are similar to those found in other mountain ranges in non-lake-effect conditions (e.g., Sinclair et al. 1997; Rotunno and Houze 2007; Neiman et al. 2002; Colle 2004; Hughes et al. 2009; Panziera and Germann 2010; Yuter et al. 2011). In contrast to the Hokuriku region, V18 did not find $\hat{H}$ to be a useful discriminator of LPE distribution and enhancement over the modest terrain of Tug Hill, as conditions were nearly always unblocked $(\hat{H}<1)$.

The geography of the Hokuriku region and the location of the YAHI radar provided an excellent location for this study, and would undoubtedly be useful in testing additional hypotheses related to the inland and orographic enhancement of sea-effect precipitation. It remains poorly understood how microphysical process influence enhancement, and what roles, if any, temperature and precipitation type play. The mode and organization of sea-effect convection also likely have an effect, if the results of V18 and Campbell et al. (2016) are any indication. Finally, the location of the Japan Sea polar airmass convergence zone (JPCZ) may also influence the enhancement, as it involves similar principles as those of lake-effect mode. Therefore future work utilizing numerical simulations of low and high enhancement cases in the Hokuriku region would provide additional insight into the mechanisms driving the enhancement.

Acknowledgments. This material is based upon work supported by the National Science Foundation under Grant AGS-1635654. Any opinions, findings, 
and conclusions or recommendations expressed in this material are those of the authors and do not necessarily reflect the views of the National Science Foundation. We thank ECMWF, JMA, NCAR, Unidata, and the University of Utah Center for High Performance Computing for the provision of datasets, software, or computer time. Mike Dixon at NCAR developed the Radx software package and provided helpful assistance. We thank scientists at SIRC for discussions and insights pertaining to sea-effect snowfall, and for the development and maintenance of the SW-Net observing sites. The JMA Niigata Local Meteorological Office developed and provided data on the history of gauge shielding at observing sites in the region. Justin Minder, Steve Krueger, John Horel, Ed Zipser, and three anonymous reviewers provided comments and input that greatly improved the manuscript.

\section{REFERENCES}

Akiyama, T., 1981a: Time and spatial variations of heavy snowfalls in the Japan Sea coastal region. Part I: Principal time and space variations of precipitation described by EOF. J. Meteor. Soc. Japan, 59, 578-590, https://doi.org/10.2151/ jmsj1965.59.4_578.

, 1981b: Time and spatial variations of heavy snowfalls in the Japan Sea coastal region. Part II: Large-scale situations for typical spatial distributions of heavy snowfalls classified by EOF. J. Meteor. Soc. Japan, 59, 591-601, https://doi.org/ 10.2151/jmsj1965.59.4_591.

Alcott, T. I., and W. J. Steenburgh, 2013: Orographic influences on a Great Salt Lake-effect snowstorm. Mon. Wea. Rev., 141, 2432-2450, https://doi.org/10.1175/MWR-D-12-00328.1.

Asai, T., 1972: Thermal instability of a shear flow turning the direction with height. J. Meteor. Soc. Japan, 50, 525-532, https:// doi.org/10.2151/jmsj1965.50.6_525.

Baines, P., 1987: Upstream blocking and airflow over mountains. Annu. Rev. Fluid Mech., 19, 75-97, https://doi.org/10.1146/ annurev.fl.19.010187.000451.

Barcilon, A., J. C. Jusem, and P. G. Drazin, 1979: On the twodimensional hydrostatic flow of a stream of moist air over a mountain ridge. Geophys. Astrophys. Fluid Dyn., 13, 125-140, https://doi.org/10.1080/03091927908243765.

Boyle, J., and T.-J. Chen, 1987: Synoptic aspects of the wintertime East Asian Monsoon. Monsoon Meteorology, C. P. Chang and T. N. Krishnamurti, Ed., Oxford University Press, $125-160$.

Byrd, G. P., R. A. Anstett, J. E. Heim, and D. M. Usinski, 1991: Mobile sounding observations of lake-effect snow bands in western and central New York. Mon. Wea. Rev., 119, 2323-2332, https://doi.org/10.1175/1520-0493(1991)119<2323:MSOOLE> 2.0.CO;2.

Campbell, L. S., and W. J. Steenburgh, 2017: The OWLeS IOP2b lake-effect snowstorm: Mechanisms contributing to the Tug Hill precipitation maximum. Mon. Wea. Rev., 145, 2461-2478, https://doi.org/10.1175/MWR-D-16-0461.1.

,$- \longrightarrow$, P. G. Veals, T. W. Letcher, and J. R. Minder, 2016: Lake-effect mode and precipitation enhancement over the
Tug Hill Plateau during OWLeS IOP2b. Mon. Wea. Rev., 144, 1729-1748, https://doi.org/10.1175/MWR-D-15-0412.1.

,$- \ldots$, Y. Yamada, M. Kawashima, and Y. Fujiyoshi, 2018: Influences of orography and coastal geometry on a transversemode sea-effect snowstorm over Hokkaido Island, Japan. Mon. Wea. Rev., 146, 2201-2220, https://doi.org/10.1175/ MWR-D-17-0286.1.

Chang, C.-P., Z. Wang, and H. Hendon, 2006: The Asian winter monsoon. The Asian Monsoon, B. Wang, Ed., Springer, 89-127.

Colle, B. A., 2004: Sensitivity of orographic precipitation to changing ambient conditions and terrain geometries: An idealized modeling perspective. J. Atmos. Sci., 61, 588-606, https:// doi.org/10.1175/1520-0469(2004)061<0588:SOOPTC>2.0.CO;2.

Cooper, K. A., M. R. Hjelmfelt, D. A. R. Kristovich, N. F. Laird, and R. G. Derickson, 2000: Numerical simulations of transitions in boundary layer convective structures in a lake-effect snow event. Mon. Wea. Rev., 128, 3283-3295, https://doi.org/ 10.1175/1520-0493(2000)128<3283:NSOTIB > 2.0.CO;2.

Crum, T. D., R. L. Alberty, and D. W. Burgess, 1993: Recording, archiving, and using WSR-88D data. Bull. Amer. Meteor. Soc., 74, 645-653, https://doi.org/10.1175/1520-0477(1993) 074<0645:RAAUWD>2.0.CO;2.

Dorman, C. E., R. C. Beardsley, N. A. Dashko, C. A. Friehe, D. Kheilf, K. Cho, R. Limeburner, and S. M. Varlamov, 2004: Winter marine atmospheric conditions over the Japan Sea. J. Geophys. Res., 109, C12011, https://doi.org/10.1029/ 2001JC001197.

Durran, D. R., and J. B. Klemp, 1982: The effects of moisture on trapped mountain lee waves. J. Atmos. Sci., 39, 2490-2506, https://doi.org/10.1175/1520-0469(1982)039<2490:TEOMOT> 2.0.CO;2.

— , and - 1983: A compressible model for the simulation of moist mountain waves. Mon. Wea. Rev., 111, 2341-2361, https://doi.org/10.1175/1520-0493(1983)111<2341:ACMFTS> 2.0.CO;2.

Earth Observing Laboratory, 2019: Radx. National Center for Atmospheric Research, accessed 7 January 2019, https:// github.com/NCAR/lrose-core/releases.

ECMWF, 2017: ERA5: Fifth generation of ECMWF atmospheric reanalyses of the global climate. Copernicus Climate Change Service (C3S), accessed 11 August 2018, https:// cds.climate.copernicus.eu/cdsapp\#!/home.

Eipper, D. T., G. S. Young, S. J. Greybush, S. S̄aslo, T. D. Sikora, and R. D. Clark, 2018: Predicting the inland penetration of long-lake-axis-parallel snowbands. Wea. Forecasting, 33, 1435-1451, https://doi.org/10.1175/WAF-D-18-0033.1.

Eito, H., T. Kato, M. Yoshizaki, and A. Adachi, 2005: Numerical simulation of the quasistationary snowband observed over the southern coastal area of the Sea of Japan on 16 January 2001. J. Meteor. Soc. Japan, 83, 551-576, https://doi.org/10.2151/ jmsj.83.551.

— M. Murakami, C. Muroi, T. Kato, S. Hayashi, H. Kuroiwa, M. Yoshizaki, 2010: The structure and formation mechanism of transversal cloud bands associated with the Japan-Sea Polar-Airmass Convergence Zone. J. Meteor. Soc. Japan, 88, 625-648, https://doi.org/10.2151/jmsj.2010-402.

Fraser, A. B., R. C. Easter, and P. V. Hobbs, 1973: A theoretical study of the flow of air and fallout of solid precipitation over mountainous terrain. Part I: Airflow model. J. Atmos. Sci., 30, 801-812, https:// doi.org/10.1175/1520-0469(1973)030<0801:ATSOTF>2.0.CO;2.

Fu, G., H. Niino, R. Kimura, and T. Kato, 2004: Multiple polar mesocyclones over the Japan Sea on 11 February 1997. Mon. 
Wea. Rev., 132, 793-814, https://doi.org/10.1175/15200493(2004)132<0793:MPMOTJ>2.0.CO;2.

Fujiyoshi, Y., T. Endoh, T. Yamada, K. Tsuboki, Y. Tachibana, and G. Wakahama, 1990: Determination of a $Z-R$ relationship for snowfall using a radar and high sensitivity snow gauges. J. Appl. Meteor. Climatol., 29, 147-152, https://doi.org/ 10.1175/1520-0450(1990)029<0147:DOARFS > 2.0.CO;2.

_, K. Tsuboki, S. Satoh, and G. Wakahama, 1992: Threedimensional radar echo structure of a snow band formed on the lee side of a mountain. J. Meteor. Soc. Japan, 70, 11-24, https://doi.org/10.2151/jmsj1965.70.1_11.

Galewsky, J., 2008: Orographic clouds in terrain-blocked flows: An idealized modeling study. J. Atmos. Sci., 65, 3460-3478, https:// doi.org/10.1175/2008JAS2435.1.

Goodison, B. E., P. Y. T. Louie, and D. Yang, 1998: WMO solid precipitation measurement intercomparison final report. Instruments and observing methods, Rep. 67, WMO/TD-872, 318 pp., http://www.wmo.int/pages/prog/www/reports/ WMOtd872.pdf.

Hughes, M., A. Hall, and R. G. Fovell, 2009: Blocking in areas of complex topography, and its influence on rainfall distribution. J. Atmos. Sci., 66, 508-518, https://doi.org/10.1175/ 2008JAS2689.1.

Inoue, S., and K. Yokoyama, 1998: Estimation of snowfall, maximum snow depth and snow cover condition in Japan under global climate change. Seppyo, 60, 367-378, https://doi.org/ 10.5331/seppyo.60.367.

Ishihara, M., H. Sakakibara, and Z. Yanagisawa, 1989: Doppler radar analysis of the structure of mesoscale snow bands developed between the winter monsoon and the land breeze. J. Meteor. Soc. Japan, 67, 503-520, https://doi.org/10.2151/ jmsj1965.67.4_503.

Iwamoto, K., S. Nakai, and A. Sato, 2008: Statistical analyses of snowfall distribution in the Niigata area and its relationship to the wind distribution. SOLA, 4, 45-48, https://doi.org/10.2151/ sola.2008-012.

Japan Meteorological Agency, 2018: Automated Meteorological Data Acquisition System (AMeDAS) surface observation data. Japan Meteorological Agency, accessed 15 May 2018, http://www.data.jma.go.jp/risk/obsdl/index.php.

Jiang, Q., 2003: Moist dynamics and orographic precipitation. Tellus, 55A, 301-316, https://doi.org/10.3402/tellusa.v55i4.14577.

Kelly, R. D., 1984: Horizontal roll and boundary-layer interrelationships observed over Lake Michigan. J. Atmos. Sci., 41, 1816-1826, https://doi.org/10.1175/1520-0469(1984) $041<1816:$ HRABLI $>2.0$. CO; 2 .

Kristovich, D. A. R., 1993: Mean circulations of boundary-layer rolls in lake-effect snow storms. Bound.-Layer Meteor., 63 , 293-315, https://doi.org/10.1007/BF00710463.

—, N. F. Laird, M. R. Hjelmfelt, R. G. Derickson, and K. A. Cooper, 1999: Transitions in boundary layer meso- $\gamma$ convective structures: An observational case study. Mon. Wea. Rev., 127, 2895-2909, https://doi.org/10.1175/1520-0493(1999) $127<2895$ :TIBLMC $>2.0$. CO;2.

Kusunoki, K., M. Murakami, M. Hoshimoto, N. Orikasa, Y. Yamada, H. Mizuno, K. Hamazu, and H. Watanabe, 2004: The characteristics and evolution of orographic snow clouds under weak cold advection. Mon. Wea. Rev., 132, 174-191, https://doi.org/10.1175/ 1520-0493(2004)132<0174:TCAEOO>2.0.CO;2.

Magono, C., K. Kikuchi, T. Kimura, S. Tazawa, and T. Kasai, 1966: A study on the snowfall in the winter monsoon season in Hokkaido with special reference to low land snowfall. J. Fac. Sci. Hokkaido Univ. Ser. 7, 11, 287-308.
Manabe, S., 1957: On the modification of air-mass over the Japan Sea when the outburst of cold air predominates. J. Meteor. Soc. Japan, 35, 311-326, https://doi.org/10.2151/ jmsj1923.35.6_311.

Markowski, P., and Y. Richardson, 2010: Mesoscale Meteorology in Midlatitudes. Wiley-Blackwell, 407 pp.

McGill, R., J. W. Tukey, and W. A. Larsen, 1978: Variations of box plots. Amer. Stat., 32, 12-16, https://doi.org/10.2307/2683468.

Metcalfe, J. R., and B. E. Goodison, 1993: Correction of Canadian winter precipitation data. Preprints, Eighth Symp. on Meteorological Observations and Instrumentation, Anaheim, CA, Amer. Meteor. Soc., 338-343.

Minder, J. R., D. R. Durran, G. H. Roe, and A. M. Anders, 2008: The climatology of small-scale orographic precipitation over the Olympic Mountains: Patterns and processes. Quart. J. Roy. Meteor. Soc., 134, 817-839, https://doi.org/10.1002/qj.258.

—, T. Letcher, L. S. Campbell, P. G. Veals, and W. J. Steenburgh, 2015: The evolution of lake-effect convection during landfall and orographic uplift as observed by profiling radars. Mon. Wea. Rev., 143, 4422-4442, https://doi.org/ 10.1175/MWR-D-15-0117.1.

Miura, Y., 1986: Aspect ratios of longitudinal rolls and convection cells observed during cold air outbreaks. J. Atmos. Sci., 43, 26-39, https://doi.org/10.1175/1520-0469(1986)043<0026:AROLRA> 2.0.CO;2.

Miyazawa, S., 1968: A mesoclimatological study on heavy snowfall. Pap. Meteor. Geophys., 19, 487-550, https://doi.org/10.2467/ mripapers1950.19.4_487.

Mizukoshi, M., 1977: Climatic division and climatography. The Climate of Japan, E. Fukui, Ed., Kondasha, 225-270.

Nagata, M., 1991: Further numerical study on the formation of the convergent cloud band over the Japan Sea in winter. J. Meteor. Soc. Japan, 69, 419-428, https://doi.org/10.2151/ jmsj1965.69.3_419.

, M. Ikawa, S. Yoshizumi, and T. Yoshida, 1986: On the formation of a convergent cloud band over the Japan Sea in winter; numerical experiments. J. Meteor. Soc. Japan, 64, 841-855, https://doi.org/10.2151/jmsj1965.64.6_841.

Nakai, S., and T. Endoh, 1995: Observation of snowfall and airflow over a low mountain barrier. J. Meteor. Soc. Japan, 73, 183-199, https://doi.org/10.2151/jmsj1965.73.2_183.

_ , and S. Yamaguchi, 2018: Aiming for a secure and comfortable life in Japan's snowy district. Snow and Weather observation Network (SW-Net). National Research Institute for Earth Science and Disaster Resilience, accessed 5 October 2018, http://www.bosai.go.jp/seppyo/index_e.html.

, K. Iwanami, R. Misumi, S.-G. Park, and T. Kobayashi, 2005: A classification of snow clouds by Doppler radar observations at Nagaoka, Japan. SOLA, 1, 161-164, https://doi.org/10.2151/ sola.2005-042.

— T. Kato, K. Iwamoto, and M. Ishizaka, 2006: A comparison of precipitation intensity from radar with model results around coastal topography during cold-air outbreak periods. 13th Conf. on Mountain Meteorology, Whistler, BC, Canada, Amer. Meteor. Soc., P1.20, https://ams.confex.com/ams/ 13MontMet17AP/webprogram/Paper141037.html.

, H. Motoyoshi, T. Kumakura, M. Ishizaka, K. Yamashita, and S. Murakami, 2018: Zh-R relations for each type of solid precipitation particle: Observational examination for less-rimed particle. Spring 2018 Meeting of the Meteorological Society of Japan, Tsukuba, Japan, Meteorological Society of Japan, B204.

Neiman, P. J., F. M. Ralph, A. B. White, D. E. Kingsmill, and P. O. G. Persson, 2002: The statistical relationship between upslope flow 
and rainfall in California's coastal mountains: Observations during CALJET. Mon. Wea. Rev., 130, 1468-1492, https://doi.org/ 10.1175/1520-0493(2002)130<1468:TSRBUF>2.0.CO;2.

Ninomiya, K., 1994: Meso-scale low family formed over the northeastern Japan Sea in the northwestern part of a parent polar low. J. Meteor. Soc. Japan, 72, 589-603, https://doi.org/ 10.2151/jmsj1965.72.4_589.

, K. Wakahara, and H. Okhubo, 1993: Meso-alpha scale low development over the northeastern Japan Sea under the influence of a parent large-scale low and a cold vortex aloft. J. Meteor. Soc. Japan, 71, 73-91, https://doi.org/10.2151/jmsj1965.71.1_73.

Niziol, T. A., 1987: Operational forecasting of lake effect snowfall in western and central New York. Wea. Forecasting, 2, 310-321, https://doi.org/10.1175/1520-0434(1987) 002<0310:OFOLES $>2.0 . \mathrm{CO} ; 2$.

— W. R. Snyder, and J. S. Waldstreicher, 1995: Winter weather forecasting throughout the eastern United States. Part IV: Lake effect snow. Wea. Forecasting, 10, 61-77, https://doi.org/ 10.1175/1520-0434(1995)010<0061:WWFTTE > 2.0.CO;2.

Ohigashi, T., and K. Tsuboki, 2005: Structure and maintenance process of stationary double snowbands along the coastal region. J. Meteor. Soc. Japan, 83, 331-349, https://doi.org/10.2151/jmsj.83.331.

- , and - 2007: Shift and intensification processes of the Japan-Sea polar-airmass convergence zone associated with the passage of a mid-tropospheric cold core. J. Meteor. Soc. Japan, 85, 633-662, https://doi.org/10.2151/jmsj.85.633.

,,-- Y. Schusse, and H. Uyeda, 2014: An intensification process of a winter broad cloud band on a flank of the mountain region along the Japan-Sea coast. J. Meteor. Soc. Japan, 92, 71-93, https://doi.org/10.2151/jmsj.2014-105.

Ohtake, H., M. Kawashima, and Y. Fujiyoshi, 2009: The formation mechanism of a thick cloud band over the northern part of the Sea of Japan during cold air outbreaks. J. Meteor. Soc. Japan, 87, 289-306, https://doi.org/10.2151/jmsj.87.289.

Panziera, L., and U. Germann, 2010: The relation between airflow and orographic precipitation on the southern side of the Alps as revealed by weather radar. Quart. J. Roy. Meteor. Soc., 136, 222-238, https://doi.org/10.1002/qj.544.

Pierrehumbert, R. T., and B. Wyman, 1985: Upstream effects of mesoscale mountains. J. Atmos. Sci., 42, 977-1003, https://doi.org/ 10.1175/1520-0469(1985)042<0977:UEOMM > 2.0.CO;2.

Purnell, D. J., and D. J. Kirshbaum, 2018: Synoptic control over orographic precipitation distributions during the Olympics Mountains Experiment (OLYMPEX). Mon. Wea. Rev., 146, 1023-1044, https://doi.org/10.1175/MWR-D-17-0267.1.

Rasmussen, R., and Coauthors, 2012: How well are we measuring snow? The NOAA/FAA/NCAR winter precipitation test bed. Bull. Amer. Meteor. Soc., 93, 811-829, https://doi.org/10.1175/ BAMS-D-11-00052.1.

Reinecke, P. A., and D. R. Durran, 2008: Estimating topographic blocking using a Froude number when the static stability is nonuniform. J. Atmos. Sci., 65, 1035-1048, https://doi.org/ 10.1175/2007JAS2100.1.

Rotunno, R., and R. A. Houze, 2007: Lessons on orographic precipitation from the Mesoscale Alpine Programme. Quart. J. Roy. Meteor. Soc., 133, 811-830, https://doi.org/10.1002/qj.67.

Rutz, J. J., W. J. Steenburgh, and F. M. Ralph, 2014: Climatological characteristics of atmospheric rivers and their inland penetration over the western United States. Mon. Wea. Rev., 142, 905-921, https://doi.org/10.1175/MWR-D-13-00168.1.

Sinclair, M. R., D. S. Wratt, R. D. Henderson, and W. R. Gray, 1997: Factors affecting the distribution and spillover of precipitation in the southern Alps of New Zealand-A case study.
J. Appl. Meteor., 36, 428-442, https://doi.org/10.1175/15200450(1997)036<0428:FATDAS >2.0.CO;2.

Smith, C. D., 2009: The relationships between snowfall catch efficiency and wind speed for the Geonor T-200B precipitation gauge utilizing various wind shield configurations. Proc. 77th Western Snow Conf., Canmore, AB, Canada, Western Snow Conference, 115-121.

Smith, R. B., 1988: Linear theory of stratified flow past an isolated mountain in isosteric coordinates. J. Atmos. Sci., 45, 3889-3896, https://doi.org/10.1175/1520-0469(1988) 045<3889:LTOSFP $>2.0$. CO;2.

Steiger, S. M., R. Hamilton, J. Keeler, and R. E. Orville, 2009: Lake-effect thunderstorms in the lower Great Lakes. J. Appl. Meteor. Climatol., 48, 889-902, https://doi.org/ 10.1175/2008JAMC1935.1.

Steiner, M., and J. Smith, 2002: Use of three-dimensional reflectivity structure for automated detection and removal of nonprecipitating echoes in radar data. J. Atmos. Oceanic Technol., 19, 673-686, https://doi.org/10.1175/1520-0426(2002) $019<0673:$ UOTDRS $>2.0 . \mathrm{CO} ; 2$.

Tachibana, Y., 1995: A statistical study of the snowfall distribution on the Japan Sea side of Hokkaido and its relation to synopticscale and meso-scale environments. J. Meteor. Soc. Japan, $\mathbf{7 3}$, 697-715, https://doi.org/10.2151/jmsj1965.73.3_697.

Takada, S., 2003: Influence of Sado Island during winter monsoon synoptic condition (in Japanese). Autumn 2003 Meeting of the Meteorological Society of Japan, Sendai, Japan, Meteorological Society of Japan, C111, http://www.bosai.go.jp/ seppyo/kenkyu_naiyou/conf_ws/kouws200403/Takada_ KousetsuWS20040308.pdf.

Tsuchiya, K., and T. Fujita, 1967: A satellite meteorological study of evaporation and cloud formation over the western Pacific under the influence of the winter monsoon. J. Meteor. Soc. Japan, 45, 232-250, https://doi.org/10.2151/ jmsj1965.45.3_232.

Vasiloff, S., 2001: WSR-88D performance in northern Utah during the winter of 1998-1999. Part I: Adjustments to precipitation estimates. NOAA/Western Regional Tech. Attachment 01-02, NOAA/NWS, 8 pp.

Veals, P. G., W. J. Steenburgh, and L. Campbell, 2018: Factors affecting the inland and orographic enhancement of lakeeffect precipitation over the Tug Hill Plateau. Mon. Wea. Rev. 146, 1745-1762, https://doi.org/10.1175/MWR-D-17-0385.1.

Villani, J. P., M. L. Jurewicz, and K. Reinhold, 2017: Forecasting the inland extent of lake-effect snow bands downwind of Lake Ontario. J. Operational Meteor., 5, 53-70, https://doi.org/ 10.15191/nwajom.2017.0505.

Von Engeln, A., and J. Teixeira, 2013: A planetary boundary layer height climatology derived from ECMWF reanalysis data. J. Climate, 26, 6575-6590, https://doi.org/10.1175/JCLI-D-1200385.1.

Watanabe, S. I., and H. Niino, 2014: Genesis and development mechanisms of a polar mesocyclone over the Japan Sea. Mon. Wea. Rev., 142, 2248-2270, https://doi.org/10.1175/MWR-D-13-00226.1.

West, T. K., W. J. Steenburgh, and G. G. Mace, 2019: Characteristics of sea-effect clouds and precipitation over the Sea of Japan region as observed by A-Train satellites. J. Geophys. Res. Atmos., 124, 1322-1335, https://doi.org/ 10.1029/2018JD029586.

Yagi, M., and R. Uchiyama, 1983: Snow clouds bypassing the Noto Peninsula and Sado Island and flow joining together-Relating to the heavy snow of the Joetsu distric (in Japanese). Tenki, 30, 291-294. 
Yamada, Y., M. Murakami, H. Mizuno, M. Maki, S. Nakai, and K. Iwanami, 2010: Kinematic and thermodynamical structures of longitudinal-mode snow bands over the Sea of Japan during cold-air outbreaks. Part I: Snow bands in large vertical shear environment in the band-transverse direction. J. Meteor. Soc. Japan, 88, 673-718, https://doi.org/10.2151/jmsj.2010-404.

Yamaguchi, S., O. Abe, S. Nakai, and A. Sato, 2011: Recent fluctuations of meteorological and snow conditions in Japanese mountains. Ann. Glaciol., 52, 209-215, https://doi.org/10.3189/ 172756411797252266.

Yanase, W., H. Niino, S. I. Watanabe, K. Hodges, M. Zahn, T. Spengler, and I.A. Gurvich, 2016: Climatology of polar lows over the Sea of Japan using the JRA-55 reanalysis. J. Climate, 29, 419-437, https://doi.org/10.1175/JCLI-D-15-0291.1.
Yokoyama, K., H. Ohno, Y. Kominami, S. Inoue, and T. Kawakata, 2003: Performance of Japanese precipitation gauges in winter (in Japanese with English abstract and captions). Seppyo, 65, 303-316.

Yoshihara, H., M. Kawashima, K. Arai, J. Inoue, and Y. Fujiyoshi, 2004: Doppler radar study on the successive development of snowbands at a convergence line near the coastal region of the Hokuriku District. J. Meteor. Soc. Japan, 82, 1057-1079, https://doi.org/10.2151/jmsj.2004.1057.

Yuter, S. E., D. A. Stark, J. A. Crouch, M. J. Payne, and B. A. Colle, 2011: The impact of varying environmental conditions on the spatial and temporal patterns of orographic precipitation over the Pacific Northwest near Portland, Oregon. J. Hydrometeor., 12, 329-351, https://doi.org/10.1175/2010JHM1239.1. 